\title{
Examining the relationship between comprehension and production processes in code-switched language
}

${ }^{a}$ Department of Hispanic Studies, Graduate Program of Linguistics, University of Puerto RicoRosa E. Guzzardo Tamargo ${ }^{\text {a }}$, Jorge R. Valdés Kroff ${ }^{\text {b }}$, \& Paola E. Dussias ${ }^{\text {c }}$ Río Piedras, P.O. Box 23351, San Juan, PR, USA 00931-3351 rosa.guzzardo@upr.edu (corresponding author)

${ }^{\mathrm{b}}$ Department of Spanish and Portuguese Studies, University of Florida, P.O. Box 117405, Gainesville, FL, USA, 32611 jvaldeskroff@ufl.edu

${ }^{c}$ Department of Spanish, Italian and Portuguese, Penn State University, 439 Burrowes Building, University Park, PA, USA, 16802

pdussias@psu.edu 


\section{Abstract}

22 We employ code-switching (the alternation of two languages in bilingual communication) to test 23 the hypothesis, derived from experience-based models of processing (e.g., Boland, Tanenhaus, 24 Carlson, \& Garnsey, 1989; Gennari \& MacDonald, 2009), that bilinguals are sensitive to the 25 combinatorial distributional patterns derived from production and that they use this information

26 to guide processing during the comprehension of code-switched sentences. An analysis of 27 spontaneous bilingual speech confirmed the existence of production asymmetries involving two 28 auxiliary+participle phrases in Spanish-English code-switches. A subsequent eye-tracking study 29 with two groups of bilingual code-switchers examined the consequences of the differences in 30 distributional patterns found in the corpus study for comprehension. Participants' comprehension 31 costs mirrored the production patterns found in the corpus study. Findings are discussed in terms 32 of the constraints that may be responsible for the distributional patterns in code-switching

33 production and are situated within recent proposals of the links between production and 34 comprehension.

35

\section{Keywords}

bilingualism

code-switching

experience-based processing models

eye-tracking

Spanish-English 
Introduction

A hallmark of proficiency in two languages is code-switching (the alternating use of two languages in bilingual speech). Proficient bilinguals often code-switch in the midst of speaking with or writing to other bilinguals. The following email illustrates the point clearly (code-

47 switched material appears in bold and capital letters for ease of presentation; translation appears

48 in square brackets).

On Mon, 9 Jul 2007 17:50:33 -0400 (sender's name omitted) wrote:

Tuesdays at 6:30 pm SUENA BIEN. If there's enough people interested in playing, maybe PODEMOS EMPEZAR tomorrow MARTES. ¿QUÉ PIENSAN? We could play in the IM building. The place TIENE three volleyball courts QUE ESTÁN available most of the time. COMO DIRÍAN LOS commentators of the Puerto Rican Volleyball Federation...

[Tuesdays at 6:30 pm SOUNDS GOOD. If there's enough people interested in playing, maybe WE CAN START tomorrow TUESDAY. WHAT DO YOU THINK? We could play in the IM building. The place HAS three volleyball courts THAT ARE available most of the time. AS THE commentators of the Puerto Rican Volleyball Federation WOULD SAY...

50 For several decades, code-switching was regarded as random interference of one language with

51 the other (e.g., Lance, 1975). We now know that code-switching is rule-governed (e.g., Deuchar,

52 Muysken, \& Wang, 2007; MacSwan, 2000; Myers-Scotton, 2002; Toribio, 2001), although there

53 is little agreement on the precise nature of the rules involved. There is consensus, however, as to

54 the observation that code-switching is a remarkable feat of bilingual communication that gives

55 language scientists the potential to understand how humans negotiate the boundaries of two

56 languages (e.g., Kroll, Dussias, Bice, \& Perrotti, 2015; Kroll, Dussias, Bogulski, \& Valdés Kroff, 57 2012). 
Code-switching presents a unique cognitive puzzle on the link between production and

77 78

comprehension. In particular, the production of code-switched speech is putatively under the control of bilingual speakers, as evidenced by their ability to speak in one language when necessary (e.g., when speaking to a monolingual conversational partner). Yet bilingual comprehenders do not a priori know when a code-switch will occur in speech. In this sense, switches can be unexpected and, thus, potentially more difficult to process than within-language sentences. In support of this, several studies on the comprehension of code-switched language have documented costs associated with processing code-switches (e.g., Altarriba, Kroll, Sholl, \& Rayner, 1996; Bultena, Dijkstra, \& Van Hell, in press; Proverbio, Leoni, \& Zani, 2004). Given the presence of switch costs, it is on the surface surprising that bilinguals rarely report experiencing difficulties comprehending code-switched discourse. In fact, bilinguals often have difficulty remembering which language was used in any particular speech exchange (Gumperz, 1982) and are often not able to unequivocally indicate the precise locus of a recently produced code-switch (Toribio, 2001). These facts suggest the existence of factors that mitigate switch costs. This logic resonates with what has been proposed in many studies of monolingual syntactic ambiguity resolution: the observation that readers garden-path only occasionally, even though temporary ambiguities are common, indicates that they use cues from production to guide their initial choices (e.g., Garnsey, Pearlmutter, Myers, \& Lotocky, 1997).

The main goal of the work presented here is to test the hypothesis, derived from experience-based models of processing (represented in the work of, e.g., Boland, Tanenhaus, Carlson, \& Garnsey, 1989; Britt, 1994; Gennari \& MacDonald, 2009; Holmes, Stowe, \& 
79 Cupples, 1989; MacDonald, Pearlmutter, \& Seidenberg, 1994; McRae, Hare, Elman, \& Ferretti, 80 2005; Novick, Thompson-Schill, \& Trueswell, 2008; Pickering \& Garrod, 2013), that bilinguals

81 are sensitive to the combinatorial distributional patterns derived from production and that they

82 use this information to guide processing during the comprehension of code-switched sentences.

83 As will be shown below, our approach exploits the power of the unique linguistic environment in

84 which bilinguals find themselves to reveal the central influence of production and its relationship

85 to the linguistic representations that speakers recruit during comprehension (e.g., Dell \& Chang,

86 2014; Levy, 2008). A second aim is to add bilingualism to the discussion of how language

87 production affects language comprehension with the purpose of broadening the evidential base.

88 The evidence in favor of experience-based models of processing has largely come from studies

89 with monolingual speakers, and predominantly from studies on syntactic ambiguity resolution or

90 the interpretation of subject/object relative clauses. Given the demographic reality that more

91 speakers around the world are bilingual, bilingualism can and should be used as a tool to uncover

92 important aspects of language function that may be obscured or difficult to study when

93 examining the behavior of individuals who speak only one language (see Kroll, Bobb, \&

94 Hoshino, 2014). In the work reported here, we use the presence of code-switching in bilingual

95 communities to test the correspondence between production patterns and comprehension

96 difficulty proposed in experience-based models of language processing.

97

98

Switch costs

99 An important distinction in the code-switching literature is the division between inter- 
100 sentential and intra-sentential switches. Inter-sentential code-switches take place at sentence

101 boundaries, as in example 1, and intra-sentential switches occur within sentence boundaries, as in

102 example 2 (in both examples, Spanish words appear in italics; the underlined portion comprises

103 the switch).

104

(1) I need to go to the pharmacy. Tengo que comprar aspirina.

106

107

108

109

110

111

112

113

114 do they develop knowledge of when code-switches are more likely to occur? If the interaction

115 between linguistic systems and the constraints that guide their successful integration during

116 code-switching can be systematically characterized, we propose that they provide a valuable

117 means of investigating questions concerning the relationship between sentence production and 118 comprehension.

119

120

(2) Mi tía dijo que my uncle left.

'My aunt said that...'

Intra-sentential switches require greater simultaneous control of both languages, creating a unique opportunity to observe the interaction between two linguistic systems. Languages across the world differ in their statistical regularities even when surface structure is similar (e.g., Dussias, Marful, Gerfen, \& Bajo, 2010). An open question, then, is how bilingual speakers successfully navigate between two languages within the same sentence. Do bilinguals follow the specific distributional statistics of one language or the other when engaged in code-switching? Or

Quantitative studies on intra-sentential switching involving a number of language pairs have revealed that certain types of syntactic junctures are more likely to serve as the loci of code-

'...(I) have to buy aspirin.' 
121 switching than others. If exposure-based models generalize to code-switched speech, then

122 bilinguals are likely to use this distributional information to guide their predictions of where

123 code-switches are more likely in comprehension. Yet most of the evidence involving switches

124 between languages points to the existence of processing costs relative to staying within the same

125 language. One source of evidence for switch costs has been reported in studies of language

126 switching during lexical decision tasks. Findings from such studies (e.g., Grainger \&

127 Beauvillain, 1988; Grainger \& O’Regan, 1992; Thomas \& Allport, 2000; von Studnitz \& Green,

128 1997) demonstrate that recognizing and integrating a linguistic code distinct from the code most

129 recently encountered incurs a processing cost for the comprehender. However, the implications

130 of these results for understanding the effect of real-world code-switched language are limited by

131 the fact that the vast majority of these studies employ decontextualized language switching tasks

132 involving words presented in isolation and where the target language is determined by the

133 experimenter (but see Gollan \& Ferreira, 2009), while actual code-switching in bilingual

134 communication is an inherently discourse-based phenomenon, where the two languages of the

135 bilingual are fully engaged, and where code-switching is entirely under the control of the

136 speaker. Given this, the switching cost triggered by a language change in the lexical switch

137 studies cited above might well be viewed as analogous to switch costs incurred in non-linguistic

138 domains (e.g., Allport, Styles, \& Hsieh, 1994) and not as a clear indication that code-switching

139 in natural discourse will necessarily incur costs in the same manner (see also Myslín \& Levy, in

140 press). 
Few, but important, studies have examined the consequences of sentence-level switching

142 for comprehension and have returned a mixed set of results. Some studies have revealed that

143 processing intra-sentential code-switches is costly. For example, in an eye-tracking reading

144 study, Altarriba, Kroll, Sholl, and Rayner (1996) demonstrated that noun switches were fixated

145 longer than synonymous within-language words; similarly, using event-related potentials,

146 Proverbio, Leoni, and Zani (2004) showed longer reaction times and increased N400 amplitudes

147 for processing code-switched words. However, other studies provide evidence that switch costs

148 can be mitigated. For example, Moreno, Federmeier, and Kutas (2002) found that the enhanced

149 late positivity that they observed for code-switched words was reduced when the switch was less

150 unexpected. Chan, Chau, and Hoosain (1983) provided evidence that reading times for long

151 stretches of mixed-language passages were the same as those for equivalent unilingual passages,

152 suggesting that discourse-level context also facilitates the processing of code-switching. In the

153 auditory domain, studies have also investigated how bilinguals comprehend a word when it is

154 spoken in a language (the "non-target" or "embedded" language) that is different from the

155 language of the preceding sentence context (e.g., Grosjean, 1988; Li, 1996; Soares \& Grosjean,

156 1984). The results indicate that the extent of activation of the non-target alternative is modulated

157 by phonetic cues available to the listener, such as the phonotactic structure of the code-switched

158 target item. From these findings, it is clear that although one can isolate costs associated with

159 code-switching, researchers have also identified conditions under which the comprehension of

160 code-switched target items is facilitated.

161 In the work presented here, we test the hypothesis that bilingual comprehenders exploit 
162 potential cues rooted in their linguistic experience with code-switched constructions to facilitate

163 the comprehension of upcoming other-language items. Cues can be present at multiple linguistic

164 levels. For example, they exist as subtle low-level cues, such as slight changes in VOT before a

165 code-switch (e.g., Balukas \& Koops, 2015; Fricke, Kroll, \& Dussias, 2015) and slow speech rate

166 (Fricke et al., 2015); they may also be discourse-driven such that certain topics are more likely

167 than others to elicit code-switches (e.g., Myers-Scotton, 1993). In addition, code-switches may

168 be used as a strategy among bilinguals to more saliently encode for meanings of low

169 predictability and high information content (Myslín \& Levy, in press). Here we examine whether

170 experience with patterns of code-switching in production prepares the comprehender for the

171 relative likelihood of encountering a code-switch in a given context. Our hypothesis is that

172 bilinguals who are exposed to code-switching are able to extract patterns of likely code-switches

173 from the exemplars of bilingual utterances in their community; these patterns, in turn, become

174 reliable indicators of when code-switches are more likely to occur in the speech of their

175 interlocutors. If bilinguals can successfully tap into knowledge about statistical regularities in the

176 production of code-switched speech, then they should be able to exploit this knowledge to

177 facilitate the comprehension of code-switched language, which should reduce or eliminate switch

178 costs. Findings such as these would suggest sensitivity to production statistics in comprehension

179 and would be congenial with proposals highlighting that exposure-based factors guide readers'

180 comprehension (Bybee, 2013; Goldberg, 2006; Langacker 1987; MacDonald, 1999, 2013;

181 MacDonald \& Seidenberg, 2006). 
Production asymmetries in code-switched speech

We capitalize on the presence of production asymmetries in code-switched discourse to examine the relationship between production and comprehension. Of particular relevance for our purposes, several studies examining the production of Spanish-English intra-sentential codeswitches (e.g., Lipski, 1978; Pfaff, 1979; Poplack, 1980) have documented an asymmetry involving alternations within the auxiliary phrase - the structure under investigation in the current study. Specifically, code-switching into an English participle preceded by the Spanish auxiliary estar 'be' (e.g., los niños están cleaning their rooms 'the children are ...') occurs as frequently in corpora as code-switches in which both the auxiliary and the participle appear in English (e.g., los niños are cleaning their rooms). However, code-switches into an English participle preceded by the Spanish perfect auxiliary haber 'have' (e.g., los niños han cleaned their rooms 'the children have...') are considerably less frequent than code-switches in which both the auxiliary and the participle appear in English (e.g., los niños have cleaned their rooms). The preponderance of switches involving progressive structures over perfect structures illustrates the differential behavior of these two switches in bilingual production. Importantly, the differences in distributional probabilities of these code-switches reflect differences in syntactic probabilities and not differences in meaning biases. That is, although the progressive and perfect forms inherently convey different temporal meanings, whether a code-switch is produced at the verb phrase boundary (i.e., at the auxiliary) or at the participle (i.e., immediately following the auxiliary) does not change the meaning of the utterance. In other words, 'los niños are cleaning their rooms' means exactly the same thing as 'los niños están cleaning their rooms' and 'los 
204 niños have cleaned their rooms' means the same as 'los niños han cleaned their rooms.' This is

205 an important point when examining the predictions of models arguing that frequency of exposure

206 to certain constructions is a major factor guiding sentence comprehension (e.g., Jurafsky, 1996;

207 MacDonald \& Seidenberg, 2006). Because the two variants (e.g., 'are cleaning' and 'están

208 cleaning') do not differ in meaning, findings that show frequency effects in comprehension can

209 be more readily attributed to particular distributional patterns in code-switched speech than to the

210 meaning conveyed by the structures themselves.

211 We will address possible reasons for the distributional patterns in production of these two

212 types of code-switches in the next section, but the critical point here is that these code-switches

213 have been reported in a variety of corpus studies to occur with different frequency. As mentioned

214 earlier, growing evidence from experience-based studies of sentence processing indicates that

215 frequency of exposure to certain word combinations modulates comprehension difficulty.

216 Whether such correspondences between comprehension and production extend to code-switching

217 is an empirical question, but the results from monolingual research lead us to predict that the

218 differential probability of producing a code-switch at a participle when it is preceded by the

219 auxiliary estar and by the auxiliary haber will result in different behaviors when bilinguals

220 comprehend these two types of code-switched structures. Participants are predicted to process

221 switches at the auxiliary and those at the participle involving the progressive structure similarly.

222 However, when the perfect structure is involved, switches at the auxiliary should incur less

223 processing disruptions relative to switches at the participle. 
Why production patterns look the way they do

One proposal that captures production asymmetries in code-switching is the 4-M model (Myers-Scotton, 1993; Myers-Scotton \& Jake, 2001). The model takes as a starting point the observation of a general constraint on the "switchability" of closed-class items (e.g., determiners, some prepositions, complementizers, etc.). From a psycholinguistic perspective, this observation is of interest because the differential behavior of closed-class words relative to open-class words has been noted in various aspects of monolingual production: (a) certain types of speech errors strand closed-class items; (b) closed-class categories resist loss or incorporation of new words; (c) in lexical decision, closed-class, but not open-class, items show frequency-independent behavior; (d) work on aphasia has shown that open- and closed-class items are differentially affected (e.g., Bradley, Garrett, \& Zurif, 1979; Joshi, 1985). Although it is generally uncontroversial that closed-class words resist code-switching, researchers have noted some puzzling exceptions. To illustrate, whereas some prepositions resist switching (e.g., the objectmarker preposition $a$ 'to' in Spanish), others switch freely (e.g., prepositions that assign theta roles, such as Spanish con 'with'). The 4-M model portrays the differential participation of closed-class items in code-switching, and the concomitant production asymmetries, by classifying closed-class items in terms of their empirically-evident syntactic roles and of hypotheses regarding how and when they are retrieved in language production. The basic insight is that not all closed-class items are equal. So-called "early system morphemes" (e.g., theta-role assigning prepositions, determiners, some auxiliaries) are salient at the level of the conceptualizer (in terms of Levelt's 1989 speech production model) and, thus, free to participate 
246 in code-switching. Conversely, "late system morphemes" (e.g., case affixes in some languages,

247 morphemes marking subject or object agreement, some auxiliaries, case marking prepositions)

248 are structurally assigned and, hence, not salient until later during language production (where

249 grammatical encoding takes place). Because of this, they do not easily participate in code-

250 switching.

251 With respect to the structures examined in this study, the model inherently predicts code-

252 switching asymmetries in production, given that the auxiliary estar, and early system morpheme,

253 is retrieved at a different stage during sentence planning than haber, a late system morpheme. By

254 locating late system morphemes in the syntactic frame, the proposal links their retrieval to

255 syntactic processing, in contrast to content and early selection morphemes, which are more

256 dependent on semantic information and are retrieved earlier. If this analysis is correct, estar

257 should be salient at the level of the mental lexicon, and switches involving the estar+English

258 participle structure should have no particular restrictions on their production. Conversely,

259 because haber functions as a placeholder in Spanish (i.e., it is void of meaning) for the

260 expression of grammatical features, the well-formedness requirements of Spanish oblige haber to

261 appear in participial structures; therefore, the entire haber+participle phrase is salient at a later

262 stage in the retrieval process, when late system morphemes are structurally-assigned in the

263 syntactic frame. This later retrieval, then, restricts code-switches between haber and an English

264 participle (We return to the 4-M model in the General discussion).

The paper is structured as follows. In the next section, we report the findings of a corpus

266 study conducted to confirm the differences reported in past code-switching literature regarding 
267 the production asymmetries discussed above. Then, we present the results of an eye-tracking

268 experiment that examined the consequences of the differences in distributional patterns found in

269 the corpus study for the comprehension of code-switched sentences. We investigate this question

270 with two groups of Spanish-English bilinguals: one group exposed to code-switched speech early

271 in life and another group exposed to code-switching later in life (during late adolescence or

272 adulthood). We predicted the following. If frequently produced code-switch types are processed

273 with more ease than less frequent ones, then haber+English participle switches (e.g., los niños

274 han cleaned 'the children have...') should produce longer reading times than their corresponding

275 phrasal boundary switches (e.g., los niños have cleaned). However, there should not be reading

276 time differences between estar+English participle switches (e.g., los niños están cleaning 'the

277 children are...') and their corresponding phrasal boundary switches (e.g., los niños are cleaning)

278 because both types of code-switches are found in spoken and written corpora with approximately

279 the same frequency of occurrence. In addition, if the amount of previous exposure to and use of

280 code-switching influences comprehension costs of code-switched sentences, then the early

281 exposure group and the late exposure group should display different reading times at the code-

282 switched region under examination. Specifically, because of their increased experience with the

283 second language and, potentially, with code-switching, the early exposure group's fixation

284 durations should better reflect the code-switching patterns found in naturalistic production

285 corpora, when compared to those of the late exposure group. We end with a general discussion of 286 our results. 
289 Corpus study

Code-switching may or may not be a community discourse mode (Poplack, 1980). When

291 it is, it is produced alongside copious stretches of unilingual discourse. This means that there are

292 no code-switching corpora per se; instead bilinguals speak to other bilinguals using stretches of

293 discourse in one of their two languages, with single-word or multi-word code-switches

294 interspersed. A good example of this is the Bangor Miami Corpus of English-Spanish

295 Codeswitching (Deuchar, Davies, Herring, Parafita Couto, \& Carter (2014). The corpus is made

296 up of approximately 43,327 utterances collected during 35 hours of bilingual speech. Of these,

297 26,801 utterances are unilingual English, 13,999 are unilingual Spanish, and 2,527 are code-

298 switched. Major categories, such as single nouns, together with subject noun phrases, object

299 noun phrases, and subordinate clauses most often participate in intra-sentential code-switching,

300 leaving a relatively small opportunity to observe code-switches at other syntactic sites, including

301 switches at the auxiliary phrase. As a way of illustration, $510(60 \%)$ of the intra-sentential code-

302 switches reported by Poplack (1980) involved major constituents, whereas only 59 switches

$303(6.9 \%)$ involving the auxiliary phrase were observed. This does not mean that generalizations

304 extracted from a small number of code-switches are not valid. The "Equivalence Constraint"

305 (Poplack, 1980), arguably one of the constraints on grammatical code-switching that has stood

306 the test of time, was based on only 851 intra-sentential code-switched utterances gathered during

30766 hours of bilingual recordings. What it means, though, is that generalizations derived from one

308 code-switching corpus need to be supported through the examination of other corpora. The 
corpus study presented below, therefore, was carried out to corroborate the production patterns described in earlier work.

We examined available oral and written Spanish-English code-switching corpora to confirm the distributional patterns involving switches at the two syntactic sites under investigation here: Spanish estar+English participle and Spanish haber+English participle. The oral corpus examined was the Bangor Miami corpus (Deuchar et al., 2014); the corpus consists of recordings of informal conversations between pairs of Spanish-English bilingual speakers living in Miami, Florida (collected in 2008). ${ }^{1}$ Twenty-six transcriptions (approximately 390,000 words) that are available on Talkbank (http://talkbank.org/browser/index.php?url= BilingBank/Bangor/Miami/) were examined. The written corpus was extracted from a weekly editorial column entitled La Calentita: Gibraltar's National Dish, which is included in the online version of the Gibraltar newspaper, Panorama (http://www.panorama.gi). This newspaper column is written in informal language, it mimics a conversation between two women who review the country's current events, and it includes numerous instances of Spanish-English codeswitching, matching the popular and frequent use of code-switching amongst locals, which they refer to as llanito (Moyer, 1995). Eighty-eight editorial column entries that appeared between 2004 and 2011 (approximately 25,300 words) were examined. Despite obvious differences between written and spoken language, the data extracted from the Miami and the Gibraltar corpora displayed similar switching patterns. Moreover, in her comparison of oral and written Gibraltarian code-switches, Moyer (1995) reported patterns of code-switches that were similar to

${ }^{1}$ A detailed description of the corpus, recruitment methods, data collection, and data transcription can be found in Deuchar et al. (2014). 
329 those described by Lipski (1985), Pfaff (1979), and Poplack (1980) for U.S. bilingual

330 communities. Importantly, our corpus analysis confirmed a claim made in past code-switching

331 literature: during code-switched speech, switches at the auxiliary and at the participle occur with

332 similar frequency when the verbal bundle comprises the progressive structure, but when it

333 involves the perfect structure, switches at the former site are much more frequent than those at

334 the latter site.

335

336 Extraction and coding procedure

337 For the analysis, we searched the transcriptions and the editorial column entries for

338 instances of the progressive structure (i.e., the Spanish auxiliary estar and the English auxiliary

339 be in its full or contracted form followed by a present participle) and the perfect structure (i.e.,

340 the Spanish auxiliary haber and the English auxiliary have in its full or contracted form followed

341 by a past participle). In the written corpus, sentence boundaries were divided by periods. In the

342 oral corpus, instances in which the transcriptions lacked punctuation that clearly demarcated the

343 beginning and end of sentences were treated following a conventional procedure in

344 sociolinguistic research whereby the entire conversational turn of a participant is defined as a

345 sentence. All grammatical subjects for the progressive and perfect structures were included in the

346 analysis (e.g., noun phrases and pronouns, all grammatical persons, animate and inanimate

347 subjects, individual and collective subjects), as well as all types of sentences (e.g., declarative

348 and interrogative, affirmative and negative). Finally, the progressive and perfect structures were 
349 included with auxiliary forms in the present, past, and future tenses and the indicative and 350 subjunctive moods.

After the initial extraction from both corpora, the following four criteria were applied to

352 the sample. Tokens of the progressive structure were excluded if they referred to a future action

353 (e.g., "I'm leaving on Friday"). The use of the progressive structure to signal future only exists in

354 English; in Spanish the future is expressed with simple future or periphrastic future

355 constructions. Because this particular use of the progressive structure could be considered an

356 environment in which a code-switch might be blocked due to lack of equivalence across

357 languages, all instances were excluded. In the case of the oral corpus, tokens were also

358 eliminated if the auxiliary was not pronounced and, therefore, not spelled out in the

359 transcriptions (e.g., “...because they offering him a big salary”). In addition, tokens were

360 excluded when they contained the perfect structure with the past participle of the verb get

361 because these phrases carried a possession meaning instead of a past action meaning (e.g., "and

362 then he's got this black and blue bruise"). Finally, tokens that comprised idioms or fixed phrases

363 with either the progressive or the perfect structure (e.g., "You are telling me, Cynthia de mi

364 corazón" ' ...of my heart') were eliminated from further analysis. In all, 36 tokens were excluded

365 from the analysis, representing less than $3 \%$ of the data. From the remaining tokens, we selected

366 only those that contained a code-switch somewhere in the sentence- in other words, sentences

367 that included both Spanish and English words. These code-switched sentences constituted the

368 code-switched corpus for the analysis. For each sentence or conversational turn, code-switches

369 with the progressive or perfect structure were coded for whether they occurred immediately 
370 before or immediately after the auxiliary phrase, at the auxiliary, at the participle, or elsewhere in

371 the sentence.

372

373 Results

374 After applying the criteria for exclusion, 845 sentences with the progressive structure and

375375 sentences with the perfect structure were extracted from the Miami oral corpus. An

376 additional 142 sentences with the progressive structure and 183 sentences with the perfect

377 structure were extracted from the Gibraltar written corpus. Because the main goal of the corpus

378 study was to verify the distributional patterns of code-switches reported in past code-switching

379 studies (e.g., Pfaff, 1979) involving the two structures, the data analyzed included only the subset

380 of sentences in which a code-switch was instantiated from Spanish to English. In the following

381 section, processing difficulty is assessed on switches going in this direction only. Table 1

382 displays the distribution of code-switches by syntactic position.

383 <Insert Table 1 here>

384 As shown in Table 1, there were numerically more code-switches involving the

385 progressive and perfect structures in the written corpus (106 and 150, respectively) than in the

386 oral corpus (93 and 28, respectively). In the written corpus, the code-switched tokens represented

387 approximately $79 \%$ of the total number of the extracted sentences, while in the oral corpus they

388 constituted a little less than $10 \%$ of the data. This difference is not surprising given that the

389 editorial column from Gibraltar was written with frequent code-switching by design; in contrast,

390 the oral corpus is a collection of conversations that took place between bilingual speakers. In 
391 compiling the corpus, the researchers simply asked the bilingual participants to speak as they

392 normally would, without explicit reference to code-switching (see Deuchar et al., 2014).

393 Whereas the number of code-switches involving the progressive structure was similar between

394 the two types of corpora (93 tokens in the oral corpus and 106 in the written corpus), there were

395 more code-switches involving the perfect structure in the written corpus (150 tokens) than in the

396 oral corpus (28 tokens), likely reflecting the topics discussed in each type of corpus. These

397 differences aside, the oral and written corpora show remarkable overlap with respect to the

398 distribution of the switch locations examined here. When the progressive structure was involved,

399 switches were just as likely to occur at the participle (e.g., los niños están cleaning... 'the

400 children are...') as switches at the auxiliary (e.g., los niños are cleaning...).

401 In the oral corpus, seven sentences included a switch at the progressive auxiliary and

402 another seven included a switch at the present participle, each of these representing $7.53 \%$ of the

403 code-switched data. Therefore, a switch was as likely to occur at the auxiliary as it was to occur

404 at the present participle. However, turning to sentences with the perfect structure, three $(10.71 \%)$

405 included a switch at the perfect auxiliary and none included a switch at the past participle. In the

406 written corpus, a very similar picture emerges. In this case, eight sentences included a switch at

407 the estar auxiliary and an additional eight sentences included a switch at the present participle,

408 each of these representing $7.55 \%$ of the code-switched data. Thus, the results of the written

409 corpus confirm that a switch at the estar auxiliary and a switch at the present participle are

410 equally probable. These percentages of occurrence are strikingly similar across the two corpora.

411 Regarding the sentences that included the perfect structure, in 15 of them, the switch occurred at 
412 the haber auxiliary, representing $10 \%$ of the code-switched data, and there was one occurrence

413 of a switch at the past participle. Once again, these results closely resemble those in the oral

414 corpus.

415 It is also worth noting that the particular examples of switches at the present participle are

416 similar across both corpora. In oral and written form, there are cases in which the estar auxiliary

417 and the English present participle are adjacent to each other and other cases in which there is

418 intervening linguistic material. In addition, in both corpora the code-switched progressive

419 structure appeared with varied grammatical subjects (i.e., noun phrases, pronouns, omitted

420 subjects) and the estar auxiliary appeared in different tenses (i.e., present, past).

421 In order to confirm these numerical trends, we conducted Fisher's exact tests (due to our

422 small sample sizes) on the production distributions for each auxiliary+participle form to test

423 whether the distributions were significantly different from each other across the oral and written

424 corpora. For both the progressive and perfect structures, there were no significant differences in

425 production distributions across the two corpora (progressive structure, $p=0.55$; perfect structure,

$426 p=0.89)$. Consequently, we combined the tokens from the oral and written corpora for the code-

427 switches at the auxiliary (e.g., los niños are cleaning...) and those at the participle (e.g., los niños

428 están cleaning...). To test whether present or perfect structure code-switches are equally likely to

429 be produced at the auxiliary or at the participle, we performed binomial tests on the success of

430 producing code-switches at the auxiliary (out of tokens comprising code-switches at the auxiliary

431 and at the participle) at more than $50 \%$ probability. The production of code-switches at the

432 auxiliary involving the progressive structure is not significantly greater than $50 \%(15 / 30, p=$ 
433 0.57). In contrast, the production of code-switches at the auxiliary involving the perfect structure 434 is significantly greater than $50 \%(17 / 18, p<0.001)$.

435 These results reveal that estar+participle switches are more frequently found in natural 436 oral and written production corpora than haber+participle switches. According to these data, 437 Spanish-English bilinguals seem to be equally likely to switch at the auxiliary or at the present 438 participle when using the progressive structure. However, when using the perfect form, they 439 avoid switching at the past participle. Instead, they switch at the auxiliary or right after the past 440 participle. In all, our findings confirm the asymmetric distribution of estar+participle switches 441 and haber+participle switches reported in past studies (Lipski, 1978, 1985; Pfaff, 1979; Poplack, 442 1980).

\section{$445 \quad$ Eye-tracking study}

Taking into consideration the differences in distributional patterns found in our corpus

447 study for the two types of switches examined here, we conducted an eye-tracking study to

448 investigate the consequences of these differences for the comprehension of code-switched

449 sentences. The specific purpose of the eye-tracking study was to examine if the type of code-

450 switch that is more frequently found in naturalistic production (i.e., a switch at the participle

451 involving the progressive structure) is processed with more ease than the type of code-switch that 452 is rarely found in code-switching corpora (i.e., a switch at the participle involving the perfect 453 structure). 
455 Methods

456 Participants

457 Two groups of Spanish-English bilinguals were recruited. One group (early exposure 458 group, n=42) had acquired Spanish and English in early childhood and had been exposed to 459 Spanish-English code-switching since childhood by virtue of being born, being raised, and living 460 in an established Spanish-English code-switching community in Harlem, New York (NY; see 461 Poplack, 1980). The second group of participants (late exposure group, $n=27$ ) was comprised by 462 speakers from Hispanic countries who had immigrated to the United States (US) later in life 463 (mean age of arrival $=18)$. The majority $(n=17)$ of the participants in the late exposure group 464 were living in the same code-switching community in Harlem. Additionally, we included ten 465 participants in this group who did not live in Harlem, but whose linguistic profile and experience 466 with code-switching were similar to the NY late exposure group (self-reported ratings and 467 proficiency measures, all $p s>0.307)$. Although they had been living in the US for less time, the 468 participants in the second group had been exposed to Spanish-English code-switching from the 469 moment of arrival in the US. Exposure-based accounts of language processing (e.g., MacDonald $470 \&$ Seidenberg, 2006) suggest that less experience with particular linguistic structures will result

471 in less sensitivity to the distributional patterns of these structures during comprehension.

472 However, the amount of previous exposure that is required to exhibit this sensitivity during 473 comprehension has not yet been addressed. The purpose of including this late exposure group, 474 then, was to ascertain the extent to which amount of time spent living in an established code- 
475 switching community (and potentially exposed to Spanish-English code-switching) affected 476 speakers' sensitivity to distributional differences in code-switching production. In other words,

477 we wanted to see if the results obtained with the group of participants who had been exposed to

478 code-switching for all or most of their lives could be replicated with a group of participants who 479 had been exposed to code-switching in the same community for less time.

480 All participants were undergraduate or graduate students from the City College of New 481 York or from Penn State University. Despite differences in their amount of exposure to code482 switching, all participants reported frequently engaging in Spanish-English code-switching with 483 other bilinguals in their adult lives, both in the spoken and the written (emails, instant messages, 484 text messages, chats) modalities. The excerpt included in the Introduction was taken from an 485 email written by a bilingual participant from this study. It serves to illustrate that code-switching 486 is present, not only in their oral exchanges, but also in these bilinguals' written interactions and, 487 thus, in their reading experience. The participants in both groups completed a series of measures 488 of language proficiency, described below.

\section{Language History Questionnaire}

In an online Language History Questionnaire (LHQ), participants provided self-ratings of

492 their English and Spanish proficiency across reading and writing production as well as speaking

493 and listening comprehension. They used a scale in which 1 corresponded to "very low" and 10

494 corresponded to "perfect." They also answered open-ended and multiple-choice questions about

495 their history with both languages, their language acquisition experiences, and their daily 
496 exposure to and use of both languages. Several examples of the questions asked in the LHQ are

497 displayed in Figure 1.

498 <Insert Figure 1 here>

499

500

Boston Naming Vocabulary Test

501

As a measure of lexical access, vocabulary size, and naming performance, participants

502 completed the Boston Naming Vocabulary Test (BNT; Kaplan, Goodglass, \& Weintraub, 1983)

503 in English and Spanish. The BNT contains 60 outline drawings of objects and animals. The

504 images were divided into two language blocks (an English block and a Spanish block) of 30

505 images each. Participants completed the BNT in their self-reported dominant language first, and

506 then in the other language. In each language block, participants were asked to name the images

507 as quickly and as accurately as possible. The drawings were presented in order of increasing

508 difficulty, starting with easy, high-frequency words, such as flower and cama ('bed') and

509 concluding with more difficult, low-frequency words like protractor and yunta ('yoke').

510 Participants' responses to the BNT were digitally recorded and these recordings were then

511 reviewed to score the test. Participants received a score of 1 for every correctly named image and

5120 for every incorrectly named image or for any unnamed image.

513

514 Grammar tests

515 Participants also completed the grammar sections of the Michigan English Language

516 Institute College Entrance Test (MELICET) and the Advanced Test of the Diplomas de Español 
517 como Lengua Extranjera (DELE, 'Diplomas of Spanish as a Foreign Language'). The MELICET

518 is an advanced level English language test created by the University of Michigan English

519 Language Institute (http://www.michigan-proficiency-exams.com/melicet.html) to examine

520 ability in different English language areas. It is primarily used to test nonnative speakers of

521 English by educational institutions as an admissions or placement test. The DELE is a

522 standardized test of Spanish issued by the Ministry of Education, Culture, and Sport of Spain,

523 which assesses proficiency in Spanish at seven levels (http://diplomas.cervantes.es/en). The test

524 administered here was the Nivel Superior C2, the highest level of accreditation. Each grammar

525 test contained 50 multiple-choice items, which evaluated grammar, vocabulary, and reading

526 competence in isolated sentences, as well as longer stretches of discourse. An example of an item

527 from each test is presented in Table 2. Participants received one point for each correct answer

528 and no points for incorrect answers.

529 <Insert Table 2 here>

530 All participants were proficient in English and Spanish and they reported regular use of

531 and exposure to both languages in the oral and written modes. More specific participant

532 characteristics are displayed in Table 3.

533 <Insert Table 3 here>

534 Table 3 shows that both groups are very similar in terms of mean age. Within-group comparisons

535 were conducted to explore differences between the participants' proficiency levels in both

536 languages. Results of paired-samples $t$ tests for the early exposure participants displayed higher

537 self-ratings and scores for English (self-ratings: $t(41)=3.62, p<.001$; BNT score: $t(41)=5.38$, 
$538 p<.001$; grammar test score: $t(41)=4.59, p<.001)$. Conversely, results for the late exposure

539 bilinguals displayed higher self-ratings and scores for Spanish (self-ratings: $t(26)=5.43, p<$

540.001 ; BNT score: $t(26)=5.47, p<.001$; grammar test score: $t(26)=2.15, p=.041)$. These

541 results demonstrate that the early exposure group was English-dominant while the late exposure

542 group was Spanish-dominant, a finding that is expected given that the former group had been

543 immersed in an English-speaking environment since birth, whereas the latter group had lived in a

544 Spanish-speaking environment and had received schooling in Spanish before coming to the US.

545 Between-group comparisons were also conducted; the results of several independent-

546 samples $t$ tests showed significant differences between both groups for almost all the proficiency

547 measures displayed in Table 3 (self-ratings for English proficiency: $t(67)=2.33, p=.023$; self-

548 ratings for Spanish proficiency: $t(67)=-4.53, p<.001$; BNT score for English: $t(67)=3.27, p=$

549.002 ; BNT score for Spanish: $t(67)=-7.89, p<.001$; DELE score: $t(67)=-6.11, p<.001)$. The

550 exception was the MELICET score, for which no significant difference between these two

551 groups was found, $t(67)=.-0.36, p=.719$. Overall, then, the two groups are proficient in both

552 languages, and display differences that are expected given their language histories and language

553 dominance.

554

555 Materials and Design

556 The experimental stimuli comprised 48 item sets (see the Appendix) for a total of 192

557 experimental sentences. Each item set consisted of four different versions of the same sentence,

558 corresponding to the four experimental conditions. Conditions 1 and 2 were code-switched 
559 conditions with the progressive structure. In Condition 1, the switch occurred at the phrasal

560 boundary (that is, at the auxiliary) and in Condition 2, it occurred at the participle. Conditions 3

561 and 4 were analogous to Conditions 1 and 2, but involved the perfect structure instead. In each

562 experimental sentence, the critical code-switched region under examination was part of an

563 embedded phrase to ensure its appearance in the middle of the sentence and, thus, in the middle

564 of the computer screen. Table 4 displays a sample item set (the critical region is underlined).

565 <Insert Table 4 here>

566 In addition to the experimental items, 32 filler sentences were added. The fillers were

567 similar to the experimental items in terms of overall length, but differed from them regarding the

568 syntactic structures and the code-switch types included. Three examples of the fillers are

569 provided below.

570 (3) Switch between the verb and the direct object

$571 \quad$ Laura estaba limpiando the kitchen before going out with her friends.

$572 \quad$ 'Laura was cleaning...'

573 (4) Switch between the definite article and the noun

$574 \quad$ Tomás y su esposa ya habían visto el movie that their friends had recommended.

575 'Thomas and his wife had already seen the...'

$576 \quad$ (5) Switch between clauses

577 Como la maestra ha sospechado, the students have not studied for the exam.

$578 \quad$ 'As the teacher has suspected...'

579 Five practice items were added at the beginning of the experiment to familiarize participants with 
the requirements of the task and the type of stimuli.

The experimental sentences were tightly controlled in several ways to ensure that extraneous factors were not responsible for the predicted pattern of results. First, the experimental stimuli were controlled for word length (mean word length 13 [range 11-14]). In addition, the verb of the main clause was always a sentential complement-biased verb or an equibiased verb, but never a direct object biased verb; this was done to facilitate processing of the following embedded clause. Also, the grammatical subjects of the verbs in the embedded clause (mean character length 10 [range 5-14]; mean lexical frequency 27.64 [range 1-162] ${ }^{2}$ ) were always a cognate noun in Spanish and English (e.g., turistas in the examples in Table 4) in order to maximize cross-linguistic lexical activation. The participles in the critical region (mean character length of the present participles 9 [range 6-11]; mean lexical frequency of the present participles 16.03 [range 1-76]; mean character length of the past participles 8 [range 5-10]; mean lexical frequency of the past participles 51.68 [range $3-401]^{3}$ ) were from regular-ending verbs in order to keep the spelling of the participles as uniform as possible.

All the sentences were followed by a comprehension question (e.g., for the items in Table 4, it was "Do the tourists seem unsatisfied?"). This was done to guarantee that participants were performing the reading task as expected. Because the sentences always began in Spanish and ended in English, the comprehension questions were presented in English to avoid introducing an

\footnotetext{
${ }^{2}$ Lexical frequencies for the Spanish grammatical subjects of the embedded clauses are from the Alameda and Cuetos (1995) two-million-word corpus, and they were obtained through the Normas e índices de interés en Psicología Experimental (NIPE) website (Díez, Fernández, \& Alonso, 2006).

${ }^{3}$ Lexical frequencies for the participles of the embedded clauses are from the HAL frequency norms (Lund \& Burgess, 1996), based on one million words, and they were obtained through The English Lexicon Project website (Balota et al., 2007).
} 
598 inter-sentential code-switch while participants were processing the question. Half of the 599 questions required a "yes" answer and the other half required a "no" answer. Questions were 600 distributed evenly such that half required a response that referenced the beginning of the 601 sentence and the other half required a response that related to the end of the sentence. Six 69602 item lists were created, each containing 32 experimental items (eight for each condition), 32 603 fillers, and the five practice sentences. Each list contained exactly one version of each of the 48 604 experimental sentence item sets. Within each file, eight item blocks were created, each 605 containing eight sentences (four experimental items and four fillers). The blocks as well as the 606 experimental items included in each block were presented in random order to each participant 607 with the constraint that no two sentences representing the same condition were presented 608 immediately following one another. This resulted in the items being presented to each participant 609 in a different order, yet the items belonging to each stimulus type were evenly distributed 610 throughout the duration of the experiment.

611

612 Procedure

613 Stimuli were presented on a color monitor using an EyeLink 1000 desktop-mounted eye614 tracker (SR Research Ltd.) interfaced with an IBM-compatible PC. Participants sat in front of the 615 computer screen and used a chin rest and a forehead pad to minimize head movement. Eye 616 movements were recorded with a camera and an infrared illuminator, located at the bottom of the 617 computer monitor. Viewing was binocular and monocular tracking of the right pupil and cornea 618 was performed at a sampling rate of $1000 \mathrm{~Hz}$. The eye-tracker was calibrated and validated for 
619 each participant at the beginning of the experimental block and after each break to calculate

620 overall equipment accuracy. Following calibration, eye position errors were less than $0.3^{\prime}$.

621 Bilinguals were seated $60 \mathrm{~cm}$ away from a 20-inch CRT monitor with $1280 \times 1024$ pixel

622 resolution. At the start of the experiment, participants completed a nine-point calibration and

623 validation procedure to allow monitoring of both horizontal and vertical eye movements. At the

624 start of each trial, a calibration point (65 pixels wide and 85 pixels tall) appeared in the left

625 corner of the screen, where the first word would appear. When a fixation was detected in this

626 calibration point, it disappeared and was replaced by the sentence. Sentences appeared in 14-

627 point Consolas font and were always presented in one line of text with 3.8 characters subtending

628 one degree of visual angle. Participants were instructed to read each sentence silently at their

629 own pace. After reading the sentence, participants were asked to answer a comprehension

630 question related to the content of the sentence. The questions were answered with either "yes" or

631 "no" by pressing one of two buttons on a game pad. In addition to the eye-tracking experiment

632 proper, participants completed the three tasks (i.e., LHQ, BNT, grammar tests) that were used to

633 assess language background and proficiency. These tasks were completed after the eye-tracking

634 experiment. Participants were paid $\$ 10$ per hour for their participation in the study.

635

636 Results

637 We report on the results of two eye-tracking reading measures for five regions of interest.

638 In example (6) below, forward slashes indicate where the sentences were segmented for analysis:

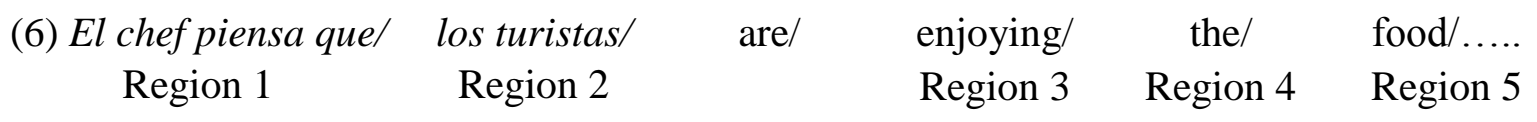


640 Region 1, the sentence initial region, combined the first four words in the sentence (Det $+\mathrm{N}+$

641 Main Verb + Comp). Region 2, the embedded subject $($ Det $+\mathrm{N})$, included words 5 and 6 and

642 constituted the region immediately preceding the critical region. Analyses on Region 1 and

643 Region 2 were conducted to rule out the possibility that any differences on the critical region

644 across conditions was caused by extraneous factors prior to the critical region. Region 3 , the

645 participle, was selected as the critical region because it is the point in the sentence at which the

646 participants have processed the complete auxiliary phrase. It is also the point at which all code-

647 switches, both the code-switches at the auxiliary and the code-switches at the participle, have

648 occurred. We initially included the auxiliary as a region for analysis; however, models did not

649 converge due to high levels of skipping (28\% for progressive structures and $29 \%$ for perfect

650 structures). Additionally, the auxiliary always appeared as one of four forms: están/are for

651 progressive structures and han/have for perfect structures. Unsurprisingly, deficient models

652 essentially revealed that readers were affected by the length of the auxiliary: longer auxiliaries

653 (i.e., están and have) were always read more slowly than shorter ones (i.e., are and han). We also

654 analyzed the two words after the critical region (Region 4 and Region 5, respectively). Because

655 processing is not always completed by the time the eyes move, the time spent processing a word

656 (or region) can spill over to the next word (Rayner \& Duffy, 1986). Therefore, analyses on

657 Regions 4 and 5 were carried out to determine whether effects not observed on the critical region

658 surfaced at a later point in the sentence and to determine whether any effects found on the critical

659 region persisted through subsequent regions. 
The two eye-tracking reading measures extracted for analysis were first-pass reading time

661

662

663

664

665

666

667 regressive fixation durations on it (Rayner \& Duffy, 1986).

668

669

670

671

672 within one character of each other. Additionally, trials for which participants incorrectly

673 answered the comprehension question were excluded from analysis, removing $9.6 \%$ of all

674 experimental trials. A repeated measures ANOVA with auxiliary (progressive, perfect) as a

675 within-subjects factor and group (early exposure, late exposure) as a between-subjects factor

676 indicated that incorrect responses to the comprehension questions were evenly distributed across

677 auxiliary and group (Auxiliary, $F(1,66)=2.67, p=0.11$; Group, $F(1,66)=1.12, p=0.29$;

678

We analyzed the two reading measures using generalized linear mixed-effects models as implemented by the lme4 package version 1.1-7 (Bates, Maechler, Boker, \& Walker, 2014) in the R Environment for Statistical Computing program, version 3.1.2 (R Core Team, 2014). Fixations shorter than $80 \mathrm{~ms}$ were combined with a previous or subsequent fixation if they were Auxiliary * Group, $F(1,66)=0.18, p=0.67)$.

\footnotetext{
${ }^{4}$ On single-word regions, first-pass reading time is equivalent to the commonly reported "gaze duration" (Liversegde, Paterson, \& Pickering, 1998; Traxler, Morris, \& Seely, 2002).
} 
We included Switch Position (at auxiliary, at participle), Group (early exposure code-

680

681

682

683

684 685

686

687

688

689

690

691

692

693

694

695

696

697

698

699

switchers, late exposure code-switchers) and Auxiliary Type (progressive, perfect), and their

interaction terms as fixed effects in the linear mixed-effects models. All factors were coded with contrast coding (-.5 for switches at the auxiliary, late exposure code-switchers, and progressive auxiliary). For the random effects structure, we first began by including random slopes for

Switch Position, Auxiliary Type and their interaction as well as random intercepts on Subjects and random slopes for Switch Position and random intercepts on Items, following a maximal random effects structure justified by the design (Barr, Levy, Scheepers, \& Tily, 2013). If models did not converge, then the random effects structure subsequently included the removal of the interaction between random slopes for Switch Position and random intercepts on Subjects.

Finally, if this model did not converge (one model), then a subsequent model that removed random slopes for Items was used. We indicate in the table summaries when models did not include the full random effects structure and report regression coefficients $(b)$ and the $t$-values for each coefficient. We report regression coefficients as significant at the .05 level for $t$-statistic values greater than or equal to 1.96 (e.g., Schotter, Bicknell, Howard, Levy, \& Rayner, 2014). In the text, we solely describe the results for first-pass reading time unless the analysis with total time led to a different result.

\section{Sentence initial and embedded subject regions (Regions 1 and 2)}

On Regions 1 and 2, we compare first-pass reading time and total time of two bilingual code-switching groups before encountering the code-switched portion of the sentences. For both 
700

701

702

703

704

705

706

707

708

709

710

711

712

713

714

715

716 717 both regions are reported in Tables 5 and 6.

$718<$ Insert Tables 5 and 6 here>

719

720

\section{Critical region (Region 3)}

regions, skipping rates ranged from $0 \%$ to $3 \%$ across all conditions and groups. For the sentence initial and the embedded subject regions, the results from the linear mixed-effects models only revealed a main effect for Group (Region 1: $b=-189.92, t=-2.07$; Region 2: $b=-133.67, t=-$ 2.47), indicating that the late exposure group read the initial Spanish regions more quickly than the early exposure group for both the progressive structure (Region 1: early exposure group switches at auxiliary $=1088 \mathrm{~ms}, \mathrm{SE}=45.98$, switches at participle $=1115 \mathrm{~ms}, \mathrm{SE}=36.85$; late exposure group - switches at auxiliary $=891 \mathrm{~ms}, \mathrm{SE}=31.81$, switches at participle $=873 \mathrm{~ms}, \mathrm{SE}$ $=36.17$; Region 2: early exposure group - switches at auxiliary $=632 \mathrm{~ms}, \mathrm{SE}=26.64$, switches at participle $=491 \mathrm{~ms}, \mathrm{SE}=18.43$; late exposure group - switches at auxiliary $=502 \mathrm{~ms}, \mathrm{SE}=$ 16.77, switches at participle $=491 \mathrm{~ms}, \mathrm{SE}=18.43)$ and the perfect structure (Region 1: early exposure group - switches at auxiliary $=1140 \mathrm{~ms}, \mathrm{SE}=40.71$, switches at participle $=1156 \mathrm{~ms}$, $\mathrm{SE}=48.23$; late exposure group - switches at auxiliary $=828 \mathrm{~ms}, \mathrm{SE}=30.35$, switches at participle $=889 \mathrm{~ms}, \mathrm{SE}=37.6$; Region 2: early exposure group - switches at auxiliary $=633 \mathrm{~ms}$, $\mathrm{SE}=26.64$, switches at participle $=652 \mathrm{~ms}, \mathrm{SE}=28.35$; late exposure group - switches at auxiliary $=561 \mathrm{~ms}, \mathrm{SE}=21.55$, switches at participle $=525 \mathrm{~ms}, \mathrm{SE}=21.66)$. Importantly, the models did not indicate any main effects or interaction with Switch Position or Auxiliary Type, suggesting no baseline differences leading up to the code-switched region. Full model outputs for 
On the critical region, we compare first-pass reading time and total time of the two

722 participant groups when encountering code-switches that occur with progressive (i.e., are/están)

723 or perfect (i.e, have/han) structures. Skipping rates for trials including the progressive structure

724 averaged $4 \%$ (range: $2-7 \%$ ) and those for trials including the perfect structure averaged 3\%

725 (range: 2-5\%). Mean reading times and standard error for the critical region are shown in Table

726 7. The results of the linear mixed-effects models for the two reading time measures are included

727 in Table 8.

728 <nsert Tables 7 and 8 here>

729 The final model revealed a Switch Position * Auxiliary Type interaction $(b=85.18, t=$

730 2.31) and no other main effects or interactions. In order to explore this interaction further, we

731 conducted post-hoc comparisons using Tukey's HSD as instantiated in the multcomp package

732 version 1.4-1 in R (Hothorn, Bretz, \& Westfall, 2008). The post-hoc tests revealed a significant

733 difference between code-switches at the participle (los turistas $\underline{\text { han enjoyed) }}$ and code-switches at

734 the auxiliary (los turistas have enjoyed) for perfect structures $(\mathrm{p}<0.001)$. Crucially, there was no

735 significant difference between the progressive structure code-switches $(p=0.13)$. Post-hoc tests

736 with total time further revealed a significant difference between perfect and progressive code-

737 switches at the participle (los turistas están enjoying / han enjoyed, $\mathrm{p}<0.001$ ). Mean reading

738 times and standard errors for both reading measures are plotted in Figures 2 and $3 .^{5}$

739 <Insert Figures 2 and 3 here>

740

\footnotetext{
${ }^{5}$ Because Group was not a significant effect, we present mean reading times collapsed for group.
} 
First and second words post-participle (Regions 4 and 5)

In the word immediately following the critical region, participants exhibited high skipping rates across all conditions (range: 44-58\%), likely due to the immediately following word being a determiner or another function word. ${ }^{6}$ The linear mixed-effects model that included first-pass reading time as a dependent variable did not reveal any main effects or interactions (all ts $<|1.63|)$. In contrast, the interaction between Switch Position and Auxiliary Type was significant for total time (Switch Position * Auxiliary Type: $b=72.14, t=2.27$ ). Post-hoc tests with Tukey's HSD indicated a significant difference between code-switches involving the perfect structure (los turistas have enjoyed / han enjoyed), with switches at the participle taking longer to read than switches at the auxiliary $(\mathrm{p}<0.001)$. Additionally, code-switches at the participle involving perfect structures (los turistas han enjoyed) were significantly slower than those involving the progressive structure (los turistas están enjoying, $\mathrm{p}<0.001$ ). As in the case of the critical region, the difference between the progressive structure code-switched conditions was not significant $(\mathrm{p}=0.56)$. Mean reading times and standard errors for the first word postparticiple region are reported in Table 9 and are plotted for first-pass reading and total time in Figures 4 and 5 respectively. <Insert Table 9 here>

\footnotetext{
${ }^{6}$ We conducted a repeated measures ANOVA including Switch Position and Auxiliary Type as withinsubjects factors and Group as a between-subjects factor. This test revealed a main effect for Switch Position $\left(F(1,66)=5, p=0.03, \eta^{2}=0.01\right)$ and a marginal effect for Auxiliary Type $(F(1,66)=3.29, p=$ $\left.0.07, \eta^{2}=0.01\right)$, indicating that participants exhibited higher skipping rates for switches at the auxiliary $(\mathrm{M}=55 \%)$ than for switches at the participle $(\mathrm{M}=50 \%)$ as well as a similar trend for progressive structures $(\mathrm{M}=55 \%)$ and perfect structures $(\mathrm{M}=50 \%)$. Although it is difficult to determine why participants exhibited differential skipping across factors, we speculate that this pattern of results reflects easier processing in conditions that exhibit higher skipping, i.e., with function words that are highly supported by their sentence context (Rayner, 1998).
} 
<Insert Figures 4 and 5 here>

In the second word following the participle, skipping rates ranged between $9 \%$ and $11 \%$ with a mean skipping rate of $9 \%$ for sentences including the progressive structure and $10 \%$ for sentences including the perfect structure. The linear mixed-effects model only indicated a main effect for Group $(b=45.06, t=1.99)$ for first-pass reading time, such that the early exposure group read this region more quickly than the late exposure group in sentences with the progressive structure (early exposure group - switches at auxiliary $=275 \mathrm{~ms}, \mathrm{SE}=11.55$, switches at participle $=290 \mathrm{~ms}, \mathrm{SE}=12.08$; late exposure group - switches at auxiliary $=315$ $\mathrm{ms}, \mathrm{SE}=15.43$, switches at participle $=349 \mathrm{~ms}, \mathrm{SE}=18.45)$ and in sentences with the perfect structure (early exposure group - switches at auxiliary $=273 \mathrm{~ms}, \mathrm{SE}=11.21$, switches at participle $=293 \mathrm{~ms}, \mathrm{SE}=12.33$; late exposure group - switches at auxiliary $=314 \mathrm{~ms}, \mathrm{SE}=$ 14.06, switches at participle $=321 \mathrm{~ms}, \mathrm{SE}=16.82)$. No other main effects or interactions were significant, and the main effect for Group was not significant for total time $(b=25.48, t=0.55$, switches at auxiliary with progressive structure $=511 \mathrm{~ms}, \mathrm{SE}=16.65$, switches at participle with progressive structure $=535 \mathrm{~ms}, \mathrm{SE}=20.02$; switches at auxiliary with perfect structure $=525$ $\mathrm{ms}, \mathrm{SE}=18.37$, switches at participle with perfect structure $=555 \mathrm{~ms}, \mathrm{SE}=19.31)$. Full model outputs for both regions are reported in Tables 10 and $11 .^{7}$

<Insert Tables 10 and 11 here>

\footnotetext{
${ }^{7}$ We note that the results for the combined regions (i.e., one two-word region) did not reveal any significant main effects or interactions for either first-pass reading time or total time, likely indicating that the spillover interaction effect from the critical region is short-lived and that the Group effect on the second word of the post-participle region is an emergent effect.
} 
To summarize, bilinguals demonstrated an asymmetry in how they process code-switched

777 sentences with the perfect structure vis-à-vis code-switched sentences with the progressive

778 structure. Specifically, in both early and late reading measures, Spanish-English bilinguals were

779 slower while reading code-switches at the participle that involved the perfect auxiliary (los

780 turistas han enjoyed) than those at the auxiliary (los turistas have enjoyed). This processing

781 difficulty extended to the word immediately following the participle for total time, indicating that

782 the processing difficulty is not short-lived, and it dissipated in the second word after the

783 participle. Importantly, the differences in fixation durations between the two conditions are not

784 present prior to the critical region. Analyses of pre-critical regions revealed group differences,

785 but these reflected language dominance, i.e., the late exposure group, as Spanish-dominant

786 speakers, read the Spanish portion of the sentences more quickly than the early exposure group,

787 and the early exposure group, as English-dominant speakers, began to read the English portion of

788 the sentences more quickly than the late exposure group. Results for the perfect structure are

789 different from those for the progressive structure, in which no significant differences between

790 switches at the auxiliary relative to switches at the participle were found in any of the five

791 regions examined. Critically, the asymmetric behavior observed in the comprehension of the

792 perfect and progressive code-switches reflects the statistical regularities found in code-switching

793 corpora; this provides support for the hypothesis that bilinguals are sensitive to the way both

794 structures are code-switched in production. 


\section{General discussion}

The way that bilingual speakers fluidly navigate between languages within a conversation presents bilingual listeners with unique challenges; because bilinguals purportedly do not provide obvious and explicit signals that they are about to produce a code-switch into the other language, the comprehension of code-switches can potentially be quite difficult due to increased ambiguity between linguistic forms. Indeed, it has been established in prior work on codeswitching that processing switches incurs costs, although there is also evidence that these costs can be mitigated. What, then, makes some code-switches easier for bilinguals to recognize and other code-switches more difficult? Our approach to begin to answer this question involved identifying statistical regularities that emerge in the production of code-switching, which

807 subsequently may be informative to bilinguals during comprehension. To address this, we capitalized on a distributional asymmetry ${ }^{8}$ in the production of code-switches involving the auxiliary phrase: whereas the Spanish auxiliary estar co-occurs with English participles in codeswitched speech, the Spanish auxiliary haber rarely does. We examined whether these statistics

811 could provide some advantage while two groups of bilinguals (bilinguals exposed to code-

812 switching from an early age and bilinguals first exposed to code-switching as young adults)

813 processed the two types of code-switches during reading. Our findings indicate that for both

814 bilingual groups, comprehension costs that surfaced during reading mirrored the production

\footnotetext{
${ }^{8}$ Asymmetries like this are not unique. In Spanish-English code-switching, grammatical gender assignment also displays production asymmetries: whereas Spanish masculine prenominal modifiers appear with English nouns whose Spanish translation equivalent is masculine ( $\mathrm{el}_{\mathrm{MASC}}$ shoe/ $\mathrm{el}_{\mathrm{MASC}}$ zapato $\left._{\mathrm{MASC}}\right)$ or feminine $\left(\mathrm{el}_{\mathrm{MASC}}\right.$ blender $_{\mathrm{FEM}} / \mathrm{la}_{\mathrm{FEM}}$ licuadora $\left._{\mathrm{FEM}}\right)$, feminine prenominal modifiers only appear with English words whose Spanish translation equivalent is feminine (la $\mathrm{FEM}_{\mathrm{FEM}}$ blender $_{\mathrm{FEM}}$, but not 'la $\mathrm{a}_{\mathrm{FEM}}$ shoe $_{\text {MASC}}$,' Valdés Kroff, in press; Valdés Kroff, Dussias, Gerfen, Perrotti, \& Bajo, in press).
} 
815 patterns found in code-switching corpora: switches at the participle were more costly when they

816 involved haber plus an English participle. The fact that both groups of bilinguals behaved

817 similarly highlights the importance of usage-based accounts of learning (Bybee, 2006), given

818 that in these accounts language emerges not as a result of language-specific mechanisms, but

819 through the interaction of cognition and use (Ibbotson, 2013).

820 One methodological aspect of our study merits some attention. Our design necessarily

821 required that the experimental items differ in important respects. Thus, we employed structures

822 that were entirely different (present perfect vs. present progressive); the English participles

823 within each structure have different morphological makeups (enjoy-ed vs. enjoy-ing) and also

824 different distributional statistics in English; the auxiliaries appeared in different languages (are-

825 están-have-han) and differed in their morphological structure in important ways (e.g., the -a in

826 están denotes the morphological class of the verb and the - n denotes person and number; the

827 English auxiliaries are morphologically simpler). Although these differences could be a source of

828 concern, in our view, the very fact that the results turned out in the predicted direction in spite of

829 the differences between the two structures underscores the central role of statistics in linguistic

830 distributions for comprehension behavior. Furthermore, as the first spillover region continued to

831 show the same pattern of results found in the critical region (i.e., no significant difference

832 between the progressive conditions, but a significant difference between the perfect conditions),

833 we interpret the overall results to indicate that the difference in the perfect conditions is due to

834 increased difficulty for code-switches at the participle. 
Why production asymmetries?

We return to the question of what factors may be responsible for the production asymmetries of the two types of code-switches observed in the corpus data. One possibility is that the differences in production arise from differences in the way that the two structures are used in Spanish and English. Specifically, the perfect structure can be used with deictic adverbial complements (e.g., hoy 'today') in certain varieties of Spanish—particularly in Peninsular varieties - to express simultaneity to the present moment; however, this use is not possible in English (Markle LaMontagne, 2011). This is illustrated in examples (8) and (9).

(8) Hoy he llamado a mi madre.

(9) *Today I have called my mother.

If equivalence facilitates code-switching (Poplack, 1980, in press), the difference between the perfect structure in Spanish and English may block the occurrence of a code-switch. This hypothesis does not seem tenable, however, once we consider that Spanish and English also display differences in the progressive structure. For example, whereas in English the present progressive can be used to refer to a future action, as shown in example (10), in Spanish the use of the progressive structure to signal future is barred (11). Future in Spanish is expressed either with a future marker on the verb (comer-é '(I) will eat') or with a periphrastic construction (vamos a viajar la próxima semana '(we) go to [= will] travel next week').

(10) Tomorrow we are eating at 1:00 p.m.

(11) *Mañana estamos comiendo a la 1:00 p.m. 
856 If the differences between the perfect and the progressive structures in English and Spanish

857 create environments that are not propitious for code-switches to occur, we would not expect the

858 production patterns reported in corpus studies to look the way they do. Moreover, our corpus

859 study and our eye-tracking experiment included only cases where the two languages could

860 combine at any level of linguistic structure and use, and where the consequences of such

861 combinations did not result in semantic incompatibilities between the two languages.

862 If there are no differences in meaning or in use linked to the occurrence of code-switches

863 involving the progressive and the perfect structures, how can we explain the differences in their

864 distributional patterns? The 4-M model of code-switching (Myers-Scotton \& Jake, 2001),

865 explained briefly in the Introduction, discusses the differential participation of closed-class items

866 in code-switching, and the resulting production asymmetries, by classifying closed-class items

867 (including auxiliaries) in terms of how and when they are activated during language production.

868 The model, which is based on Levelt's (1989) speech production model, takes as a starting point

869 the observation that language specific properties can interact with production mechanisms to lead

870 to differences with regard to information flow during sentence production (Vigliocco,

871 Butterworth, \& Garrett, 1996) — an observation that has received independent support from prior

872 cross-linguistic research (e.g., Costa, Sebastián-Gallés, Miozzo, \& Caramazza, 1999; Miozzo \&

873 Caramazza, 1999; Schiller \& Caramazza, 2003). Lexical access and grammatical encoding

874 during production are located in the formulation component (Levelt, 1989). This component

875 takes a speaker's non-linguistic conceptual message and transforms it into linguistic structure.

876 Words are accessed and ordered, and their sounds are retrieved and organized for articulation. 
877 The formulation component is distinguished from a prior component responsible for message

878 formation (the conceptualizer) and from a subsequent one that executes articulatory movements

879 (Dell, Chang, \& Griffin, 1999). The formulation component is commonly thought of as

880 involving two stages, a functional stage of processing and a positional stage. During functional

881 processing, speakers lexicalize concepts and generate functional structure (e.g., syntactic

882 information is specified and syntactic roles are assigned). During positional processing, the

883 retrieved lexical items are inflected and assembled into their appropriate position in the sentence

884 (see Jaeger \& Norcliffe, 2009). The output of these two stages is then passed onto the phonetic

885 encoding and the articulatory processing (Bock \& Levelt, 1994).

886

Returning now to the Spanish auxiliary system, according to Myers-Scotton and Jake

887 (2001), not all closed-class items are equal. Early system morphemes are free to participate in

888 code-switching, but late system morphemes, which are void of meaning and fulfill purely

889 syntactic functions, are structurally assigned and, hence, do not easily participate in code-

890 switching. The classification of estar as an early system morpheme and haber as a late system

891 morpheme is based on their respective within-language behavior. Although both are poly-

892 morphemic and convey tense and aspect, haber has lost its original meaning of 'to have,' or 'to

893 possess' (Coromines \& Pascual, 1980). Modern day Spanish expresses possession using tener

894 (e.g., él tiene una mascota 'he has a pet'). New verbs have also replaced periphrastic uses of

895 haber; hence, haber alegría 'to have happiness' is expressed in contemporary Spanish with

896 alegrarse; haber miedo 'to have fright' has become asustarse, and haber nombre 'to have a

897 name' is llamarse (García Gallarín, 2002, p. 20). In Spanish, haber as a lexical verb is only 

assigned; because of this, the entire haber verb phrase does not easily participate in code-

employed as an existential (hay cinco libros 'there are five books'), and in archaic (and nonproductive) phrases to express obligation (e.g., has de verla 'you have to see her'). The argument is that haber is simply a "placeholder" for grammatical features to be expressed orthographically and phonologically during the positional stage in production. These properties of haber considerably limit the possibility of a code-switch to be produced. In contrast to haber, estar is more autonomous in its syntactic behavior. First, aside from being followed by the present participle (estoy trabajando 'I am working'), estar can be followed by other expressions, such as adverbial and adjectival phrases (e.g., estoy en el parque 'I am at the park,' and estoy molesto 'I am angry'). In addition, intervening material is permissible between estar and a present participle (e.g., ella está siempre fastidiándonos 'she is always bothering us'). Estar and the present participle can also switch syntactic positions, something not permissible with haber (e.g., caminando estoy 'walking (I) am'). This indicates that estar is semantically more autonomous, allowing for a code-switch to occur effortlessly in this context. If this analysis is correct, estar is salient at the level of the mental lexicon, and switches involving the estar+participle constructions should have no particular restrictions on their production, i.e., no restrictions against code-switching, as is the case in other well-attested syntactic positions, such as switches between a subject noun phrase and its corresponding verb phrase. Haber, on the other hand, has purely grammatical functions and is salient only when late selected morphemes are structurally917 switching. 
Admittedly, the production explanation provided here remains necessarily tentative

919 because our understanding of the production forces that promote code-switching is in a very

920 early stage. One general, albeit counter-intuitive hypothesis, is that bilinguals engage in code-

921 switching partly to improve production fluency. We know that bilinguals are actually not capable

922 of "turning off" another language entirely, even when the intention is to speak one language only

923 (Kroll \& Bialystok, 2013; Kroll, Bobb, Wodniecka, 2006; Kroll 2008). Given the parallel

924 activity of a bilingual's two languages, it may be that bilinguals code-switch, in part, to mitigate

925 utterance planning difficulties that come from the parallel activation of their two languages. The

926 fact that not all bilinguals code-switch suggests the presence of social forces and community-

927 based norms that also affect whether or not bilinguals engage in code-switching (Myers-Scotton,

928 1993; Torres Cacoullos \& Travis, 2015). But when code-switching is part of the linguistic

929 repertoire of bilingual communities, it may be a strategy used to mitigate utterance planning

930 difficulties that come from having words and sentence structures activated in parallel in both

931 languages. In this sense, costs associated with the production of code-switches should be the

932 exception and not the norm. We hope that the study of the relationship between the

933 comprehension and production of code-switched language presented here has the consequence of 934 increasing interest from production researchers to investigate the production forces that promote 935 code-switching.

936

937 Linking production patterns to comprehension difficulty 
The results of the eye-tracking study are congenial with models that propose that the 939 relative frequency of constructions, as quantified within a corpus, modulates comprehension 940 costs. The Production-Distribution-Comprehension (PDC) model (Gennari \& MacDonald, 2009; 941 MacDonald, 2013; MacDonald \& Thornton, 2009) is one such model. According to the PDC 942 model, the properties and mechanisms of the production system influence the structural choices 943 that individuals make during production, promoting certain lexical or structural pairings over 944 others. These production pressures, over time and across many speakers and writers, create 945 distributional patterns in the language input that comprehenders perceive. The distributional 946 patterns become the probabilistic constraints that guide comprehension in a constraint-based 947 system. Comprehenders implicitly learn from these patterns and interpret new input as consistent 948 with previous experience. Therefore, factors beyond the structural properties of language, such 949 as prior experience with particular structures, are considered to play a crucial role in the 950 comprehension of those structures. In other words, frequent linguistic structures are more readily 951 activated than less common structures, and are, therefore, easier to process during 952 comprehension. A similar notion is taken up in the P-chain framework (Dell \& Chang, 2014), 953 which discusses the relation between psycholinguistic concepts, such as processing, prediction, 954 and production. A central aspect of the framework for the purposes of this study is the proposal 955 that processing involves prediction regarding upcoming structures and that this prediction is 956 influenced by the production systems of other speakers, which create production-biased 957 distributions that train comprehenders' processing systems. This experience in predicting, in 
958 turn, trains production, resulting in a system in which both production and comprehension are

959 linked to each other and affected by previous linguistic experience.

Both of these approaches can be invoked to explain the eye-tracking results reported here.

961 As the corpus study showed, switches at the auxiliary involving the progressive structure are as

962 frequent in the bilinguals' linguistic experience (be it others' production practices or their own)

963 as switches at the participle; switches involving the perfect structure, however, are frequent if

964 they occur at the auxiliary, but infrequent at the participle. The relative frequency of these

965 switches in production obviously plays a key role. What is striking about the findings is the

966 evidence that bilinguals have developed sensitivity to detailed distributional information about

967 these two types of code-switches and that this modulates the bilinguals' comprehension

968 difficulty.

969 In concluding, a word is in order about the importance of converging evidence. Over

970 forty years of sentence-processing research has given rise to multiple models about the

971 architecture of the sentence-processing mechanism. For the vast majority of this period, the

972 evidential base in favor of one model or another has come from studies involving monolingual

973 speakers. During this time, many creative experimental designs using powerful data collection

974 tools have generated data that have been used to adjudicate among competing models. As might

975 be expected, some results are firmly in the camp that proposes one particular model, but, of

976 course, there is an extensive body of work that also favors an opposing model. In the very end,

977 the model that will prevail is likely to be the one capable of accounting for the most findings.

978 The work we presented here illustrates how we can expand the study of basic language processes 
979 by exploiting the presence of two languages in a single mind. Our findings broadly suggest that 980 bilingual code-switchers learn and store frequency information about multi-word code-switches, 981 which they later use during comprehension. By looking at bilingual data, then, we add evidence 982 to the processing literature that broadly supports a usage-based position.

983

984 Acknowledgments

985 This research was supported in part by NSF Dissertation Award BCS-1123874 to Rosa E.

986 Guzzardo Tamargo and Paola E. Dussias; NSF Dissertation Award BCS-1124218 to Jorge R.

987 Valdés Kroff and Paola E. Dussias; NSF grant BCS-0821924, NSF grant BCS-0955090, and

988 NSF grant OISE-0968369 to Paola E. Dussias; NIH grant 5R21HD071758 to Paola E. Dussias;

989 and NSF Minority Postdoctoral Research Fellowship SMA-1203634 to Jorge R. Valdés

990 Kroff. We would like to thank Rena Torres Cacoullos and John Lipski for comments on this

991 work. We also thank two anonymous reviewers and Antje Meyer for many helpful comments on 992 previous versions of this manuscript. All errors remain our own. 
995 Alameda J. R. \& Cuetos, F. (1995). Diccionario de frecuencias de las unidades lingüísticas del castellano. Oviedo, Spain: Servicio de Publicaciones de la Universidad de Oviedo.

Allport, D. A., Styles, E. A., Hsieh, S. (1994). Shifting intentional set: Exploring the dynamic control of tasks. In C. Umiltà \& M. Moscovitch (Eds.), Attention and performance 15: Conscious and nonconscious information processing. Attention and performance series (pp. 421-452). Cambridge, MA: MIT Press.

Altarriba, J., Kroll, J. F., Sholl, A., \& Rayner, K. (1996). The influence of lexical and conceptual 1002 constraints on reading mixed-language sentences: Evidence from eye fixations and naming times. Memory \& Cognition, 24(4), 477-492.

Balota, D. A., Yap, M. J., Cortese, M. J., Hutchison, K. A., Kessler, B., Loftis, B.,...Treiman, R. (2007). The English Lexicon Project. Behavior Research Methods, 39(3), 445-459.

Balukas, C., \& Koops, C. (2015). Spanish-English bilingual voice onset time in spontaneous code-switching. International Journal of Bilingualism, 19, 423-443. doi:1367006913516035

Barr, D. J., Levy, R., Scheepers, C., \& Tily, H. J. (2013). Random effects structure for confirmatory hypothesis testing: Keep it maximal. Journal of Memory and Language 2 $68(3), 255-278$

Bates, D., Maechler, M., Bolker, B., \& Walker, S. (2014). lme4: Linear mixed-effects models using Eigen and S4. R package version 1.1-7. <http://CRAN.R-project.org/ package $=$ lme4> 
1015 Bock, K., \& Levelt, W. (1994). Language production: Grammatical encoding. In M. A.

1016

1017

1018

1019

1020

1021

1022

1023

1024

1025

1026

1027

1028

1029

1030

1031

1032

1033

1034

Gernsbacher (Ed.), Handbook of Psycholinguistics (pp. 945-984). San Diego, CA: Academic Press.

Boland, J. E., Tanenhaus, M. K., Carlson, G., \& Garnsey, S. M. (1989). Lexical projection and the interaction of syntax and semantics in parsing. Journal of Psycholinguistic Research, $18(6), 563-576$.

Bradley, D., Garrett, M., \& Zurif, E. B. (1979). Syntactic limitations in Broca's aphasia. In D. Caplan (Ed.), Biological Studies of Mental Processes. Cambridge, MA: MIT Press.

Britt, M. A. (1994). The interaction of referential ambiguity and argument structure in the parsing of prepositional phrases. Journal of Memory and Language, 33(2), 251-283.

Bultena, S., Dijkstra, T., \& Van Hell, J. G. (in press). Switch cost modulations in bilingual sentence processing: Evidence from shadowing. Language, Cognition, and NeuroScience.

Bybee, J. (2006). From usage to grammar: The mind's response to repetition. Language, 82, 711733.

Bybee, J. (2013). Usage-based theory and exemplar representation. In T. Hoffman \& G. Trousdale (Eds.), The Oxford Handbook of Construction Grammar (pp. 49-69). Oxford, UK: Oxford University Press.

Caramazza, A. (1997). How many levels of lexical processing are there in lexical access? Cognitive Neuropsychology, 14, 177-208. 
1035 Chan, M., Chau, H. L. H., \& Hoosain, R. (1983). Input/Output switch in bilingual code 1036 switching. Journal of Psycholinguistic Research, 12(4), 407-416.

1037 Coromines, J., \& Pascual, J. A. (1980). Diccionario crítico etimológico castellano e hispánico. 1038 Madrid, Spain: Gredos.

1039 Costa, A., Sebastián-Gallés, N., Miozzo, M., \& Caramazza, A. (1999). The gender congruity 1040 effect: Evidence from Spanish and Catalan. Language \& Cognitive Processes, 14, 3811041391.

1042 Dell, G. S., \& Chang, F. (2014). The P-chain: Relating sentence production and its disorders to 1043 1044 1045 1046 1047 1048 1049 1050 comprehension and acquisition. Philosophical Transactions of the Royal Society B, 369(1634). doi:0.1098/rstb.2012.0394

Dell, G. S., Chang, F., \& Griffin, Z. M. (1999). Connectionist models of language production: lexical access and grammatical encoding. Cognitive Science, 23(4), 517-542. doi:10.1016/S0364-0213(99)00014-2

Deuchar, M., Davies, P., Herring, J. R., Parafita Couto, M. C., \& Carter, D. (2014). Building bilingual corpora. In E. Thomas \& I. Mennen (Eds.), Unraveling Bilingualism: A CrossDisciplinary Perspective (pp 93-110). Bristol, UK: Multilingual Matters.

1051 Deuchar, M., Muysken, P., \& Wang, S-L. (2007). Structured variation in codeswitching: Towards an empirically based typology of bilingual speech patterns. International Journal of Bilingual Education and Bilingualism, 10(3), 298-340.

1054 Díez, E., Fernández, A., \& Alonso, M. A. (2006). NIPE: Normas e índices de interés en 1055 Psicología Experimental. Retrieved from <http://www.usal.es/gimc/nipe/> 
Dussias, P. E., Marful, A., Gerfen, C., \& Bajo Molina, M. T. (2010). Usage frequencies of complement-taking verbs in Spanish and English: Data from Spanish monolinguals and Spanish-English bilinguals. Behavior Research Methods, 42, 1004-1011.

Fricke, M., Kroll., J. F., \& Dussias, P. E. (2015). Phonetic variation in bilingual speech: A lens for studying the production-comprehension link. Journal of Memory and Language. doi:10.1016/j.jml.2015.10.001

García Gallarín, C. (2002). Usos de haber y tener en textos medievales y clásicos. Iberoromania, $55,1-28$.

Garnsey, S. M., Pearlmutter, N. J., Myers, E., \& Lotocky, M. A. (1997). The contributions of verb bias and plausibility to the comprehension of temporarily ambiguous sentences. Journal of Memory and Language, 37, 58-93.

Garrett, M. F. (1975). The analysis of sentence production. In G. H. Bower (Ed.), The psychology of learning and motivation (pp. 133-175). San Diego, CA: Academic Press.

Gennari, S. P., \& MacDonald, M. C. (2009). Linking production and comprehension processes: The case of relative clauses. Cognition, 111, 1-23.

Goldberg, A. E. (2006). Constructions at Work: The Nature of Generalization in Language. Oxford, UK: Oxford University Press.

Gollan, T. H., \& Ferreira, V. S. (2009). Should I stay or should I switch? A cost-benefit analysis of voluntary language switching in young and aging bilinguals. Journal of Experimental Psychology: Learning, Memory, and Cognition, 35(3), 640-665. 
1076 Grainger, J., \& Beauvillain, C. (1988). Associative priming in bilinguals: Some limits of 1077 interlingual facilitation effects. Canadian Journal of Psychology / Revue Canadienne de $1078 \quad$ Psychologie, 42(3), 261-273.

1079 Grainger, J., \& O’Regan, J. K. (1992). A psychophysical investigation of language priming 1080 effects in two English-French bilinguals. The European Journal of Cognitive Psychology, $1081 \quad 4(4), 323-339$.

1082 Grosjean, F. (1988). Exploring the recognition of guest words in bilingual speech. Language and 1083 Cognitive Processes, 3(3), 233-274.

1084 Gumperz, J. (1982). Conversational code-switching. In J. Gumperz (Ed.), Discourse Strategies 1085 (pp. 59-99). Cambridge, UK: Cambridge University Press.

1086 Holmes, V. M., Stowe, L., \& Cupples, L. (1989). Lexical expectations in parsing complement1087 verb sentences. Journal of Memory and Language, 28, 668-689.

1088 Hothorn, T., Bretz, F., \& Westfall, P. (2008). Simultaneous interference in general parametric 1089 models. Biometrical Journal, 50(3), 346-363.

1090 Ibbotson, P. (2013). The scope of usage-based theory. Frontiers in Psychology, 4, 1-15.

1091 doi:10.3389/fpsyg.2013.00255

1092 Jaeger, T. F., \& Norcliffe, E. J. (2009). The cross-linguistic study of sentence production.

1093 Language and Linguistics Compass, 3(4), 866-887. doi:10.1111/j.1749-

1094 818X.2009.00147.x

1095 Joshi, A. K. (1985). Processing of sentences with intrasentential code-switching. In D. R. Dowty, 1096 L. Karttunen, \& A. M. Zwicky (Eds.), Natural Language Parsing: Psychological, 

University Press.

1099 Jurafsky, D. (1996). A probabilistic model of lexical and syntactic access ambiguity. Cognitive $1100 \quad$ Science, 20, 137-194.

1101 Kaplan, E., Goodglass, H., \& Weintraub, S. (1983). Boston Naming Test. Philadelphia, PA: Lea 1102 \& Febiger.

1103 Kroll, J. F. (2008). Juggling two languages in one mind. Psychological Science Agenda, American Psychological Association, 22. Retrieved from <http://www.apa.org/science/ about/psa/2008/01/kroll.aspx>

Kroll, J. F., \& Bialystok, E. (2013). Understanding the consequences of bilingualism for language processing and cognition. Journal of Cognitive Psychology, 25, 497-514. investigate language, cognition and the brain. Current Directions in Psychological Science, 23, 1659-1163.

1112 Kroll, J. F., Bobb, S. C., \& Wodniecka, Z. (2006). Language selectivity is the exception, not the rule: Arguments against a fixed locus of language selection in bilingual speech.

1115 Kroll, J. F., Dussias, P. E., Bice, K., \& Perrotti, L. (2015). Bilingualism, Mind, \& Brain. Annual Review of Linguistics, 1, 337-394. doi:10.1146/annurev-linguist-030514-124937 
1117 Kroll, J. F., Dussias, P. E., Bogulski, C. A., \& Valdés Kroff, J. R. (2012). Juggling two

1118 languages in one mind: What bilinguals tell us about language processing and its consequences for cognition. In B. Ross (Ed.), The Psychology of Learning and Motivation, 56 (pp. 229-262). San Diego, CA: Academic Press. Center for Applied Linguistics.

1125 Levelt, W. J. M. (1989). Speaking: From Intention to Articulation. Cambridge, MA: MIT Press.

1126 Levy, R. (2008). Expectation-base syntactic comprehension. Cognition, 106, 1126-1177.

1127 Li, P. (1996). Spoken word recognition of code-switched words by Chinese-English bilinguals. Journal of Memory and Language, 35, 757-774.

1129 Lipski, J. M. (1978). Code-switching and the problem of bilingual competence. In M. Paradis (Ed.), Aspects of bilingualism (pp. 250-264). Columbia, SC: Hornbeam Press. Center for Latin American Studies, Arizona State University.

1133 Lund, K., \& Burgess, C. (1996). Producing high-dimensional semantic spaces from lexical cooccurrence. Behavior Research Methods, Instrumentation, and Computers, 28, 203-208.

1135 MacDonald, M. C. (1999). Distributional information in language comprehension, production, and acquisition: Three puzzles and a moral. In B. MacWhinney (Ed.), The emergence of language (pp. 177-196). Mahwah, NJ: Lawrence Erlbaum. 
1138 MacDonald, M. (2013). How language production shapes language form and comprehension.

1139 Frontiers in Psychology, 4, 1-16. doi:10.3389/fpsyg.2013.00226

1140 MacDonald, M. C., Pearlmutter, N. J., \& Seidenberg, M. S. (1994). Lexical nature of syntactic 1141 ambiguity resolution. Psychological Review, 101, 676-703.

1142 MacDonald, M. C., \& Seidenberg, M. S. (2006). Constraint satisfaction accounts of lexical and 1143 sentence comprehension. In. M. J. Traxler \& M. A. Gernsbacher (Eds.), Handbook of 1144 Psycholinguistics (2 ${ }^{\text {nd }}$ ed.) (pp. 581-611). London, UK: Elsevier.

1145 MacDonald, M. C., \& Thornton, R. (2009). When language comprehension reflects production 1146 constraints: Resolving ambiguities with the help of past experience. Memory \& $1147 \quad$ Cognition, 37, 1177-1186.

1148 MacSwan, J. (2000). The architecture of the bilingual language faculty: Evidence from 1149 intrasentential code switching. Bilingualism: Language and Cognition, 3(1), 37-54.

1150 Markle LeMontagne, J. (2011). Acquisition of the Spanish present perfect by Spanish-English 1151 bilinguals. Proceedings of the 2011 Annual Conference of the Canadian Linguistic Association, 1-15.

1153 McRae, K., Hare, M., Elman, J. L., \& Ferretti, T. R. (2005). A basis for generating expectancies 1154 for verbs from nouns. Memory \& Cognition, 33, 1174-1184.

1155 Miozzo, M., \& Caramazza, A. (1999). The selection of determiners in noun phrase production. 1156 Journal of Experimental Psychology: Learning, Memory, \& Cognition, 25, 907-922. 
1157 Moreno, E. M., Federmeier, K. D., \& Kutas, M. (2002). Switching languages, switching palabras 1158 (words): An electrophysiological study of code switching. Brain and Language, 80(2), $1159 \quad 188-207$.

1160 Moyer, M. G. (1995). Analysis of code-switching in Gibraltar. (Doctoral dissertation). Retrieved 1161 from Linguistics and Language Behavior Abstracts. (9510660)

1162 Myers-Scotton, C. (1993). Social Motivations for Code-switching: Evidence from Africa. 1163 Oxford, UK: Claredon Press.

1164 Myers-Scotton, C. (2002). Frequency and intentionality in (un)marked choices in codeswitching:

1165 "This is a 24-hour country". International Journal of Bilingualism, 6(2), 205-219.

1166 Myers-Scotton, C., \& Jake, J. L. (2001). Explaining aspects of code-switching and their

1167 implications. In J. L. Nicol (Ed.), One mind, two languages: Bilingual language 1168 processing (pp. 84-116). Oxford, UK: Blackwell.

1169 Myslín, M., \& Levy, R. (in press). Codeswitching and predictability of meaning in discourse. $1170 \quad$ Language.

1171 Novick, J. M., Thompson-Schill, S. L., \& Trueswell, J. C. (2008). Putting lexical constraints in 1172 context into the visual-world paradigm. Cognition, 107(3), 850-903.

1173 Pfaff, C. W. (1979). Constraints on language mixing: Intrasentential code-switching and $1174 \quad$ borrowing in Spanish/English. Language, 55(2), 291-318.

1175 Pickering, M. J., \& Garrod, S. (2013). An integrated theory of language production and 1176 comprehension. Behavioral and Brain Sciences, 36(4), 329-347. 
1177 Poplack, S. (1980). Sometimes I'll start a sentence in Spanish y termino en español: Toward a $1178 \quad$ typology of code-switching. Linguistics, 18(7-8), 581-618.

1179 Poplack, S. (in press). Code-switching (Linguistics). In International Encyclopedia of Social and 1180 Behavioral Sciences. (2 ${ }^{\text {nd }}$ ed.) Elsevier Science.

1181 Proverbio, A. M., Leoni, G., \& Zani, A. (2004). Language switching mechanisms in 1182 simultaneous interpreters: An ERP study. Neuropsychologia, 42(12), 1636-1656.

1183 R Core Team (2014). R: A language and environment for statistical computing. [Computer software]. Retrieved from <http://www.R-project.org>

1185 Rayner, K. (1998). Eye movements in reading and information processing: 20 years of research. Psychological Bulletin, 124(3), 372-422.

1187 Rayner, K., \& Duffy, S. A. (1986). Lexical complexity and fixation times in reading: Effects of 1188 word frequency, verb complexity, and lexical ambiguity. Memory \& Cognition, 14(3), 191-201.

Schotter, E. R., Bicknell, K., Howard, I., Levy, R., \& Rayner, K. (2014). Task effects reveal cognitive flexibility responding to frequency and predictability: Evidence from eye movements in reading and proofreading. Cognition, 131, 1-27.

1193 Schiller, N. O., \& Caramazza, A. (2003). Grammatical feature selection in noun phrase production: Evidence from German and Dutch. Journal of Memory \& Language, 48, 169194.

1196 Soares, C., \& Grosjean, F. (1984). Bilinguals in a monolingual and a bilingual speech mode: The 1197 effect of lexical access. Memory \& Cognition, 12(4), 380-386. 
Thomas, M. S. C., \& Allport, D. A. (2000). Language switching costs in bilingual visual world recognition. Journal of Memory and Language, 43(1), 44-66.

Toribio, A. J. (2001). On the emergence of bilingual code-switching competence. Bilingualism, $4(3), 203-231$.

Torres Cacoullos, R., \& Travis, K. (2015). Gauging convergence on the ground: Code-switching in the community. International Journal of Bilingualism, 19, 365-386.

Traxler, M. J., Morris, R. K., \& Seely, R. E. (2002). Processing subject and object relative clauses: Evidence from eye movements. Journal of Memory and Language, 47, 69-90.

Valdés Kroff, J. R. (in press). Mixed NPs in Spanish-English bilingual speech: Using a corpusbased approach to inform models of sentence processing. Manuscript submitted for publication in R. E. Guzzardo Tamargo, C. M. Mazak, \& M. C. Parafita Couto (Eds.), Spanish-English Codeswitching in the Caribbean and the United States. John Benjamins.

Valdés Kroff, J. R., Dussias, P. E., Gerfen, C., Perrotti, L., \& Bajo Molina, M. T. (in press). Experience with code-switching modulates the use of grammatical gender during sentence processing. Linguistic Approaches to Bilingualism.

Vigliocco, G., Butterworth. B, \& Garrett, M. (1996). Subject-verb agreement in Spanish and English: Differences in the role of conceptual factors. Cognition, 51, 661-298.

von Studnitz, R. E., \& Green, D. (1997). Lexical decision and language switching. International Journal of Bilingualism, 1(1), 3-24. 


\section{Tables}

1218

1219 Table 1. Distribution of code-switches by syntactic site (Spanish to English switches)

\begin{tabular}{|c|c|c|c|c|c|c|c|c|}
\hline & \multicolumn{4}{|c|}{ Oral Corpus (Miami) } & \multicolumn{4}{|c|}{ Written Corpus (Gibraltar) } \\
\hline & \multicolumn{2}{|c|}{ Progressive } & \multicolumn{2}{|c|}{ Perfect } & \multicolumn{2}{|c|}{ Progressive } & \multicolumn{2}{|c|}{ Perfect } \\
\hline & Tokens & $\%$ & Tokens & $\%$ & Tokens & $\%$ & Tokens & $\%$ \\
\hline $\begin{array}{l}\text { Switch } \\
\text { immediately } \\
\text { preceding } \\
\text { auxiliary }\end{array}$ & 3 & $3.22 \%$ & 0 & -- & 1 & $0.94 \%$ & 1 & $.667 \%$ \\
\hline $\begin{array}{l}\text { Switch at } \\
\text { auxiliary }\end{array}$ & 7 & $7.53 \%$ & 3 & $10.71 \%$ & 8 & $7.55 \%$ & 14 & $9.33 \%$ \\
\hline $\begin{array}{l}\text { Switch at } \\
\text { participle }\end{array}$ & 7 & $7.53 \%$ & 0 & -- & 8 & $7.55 \%$ & 1 & $.667 \%$ \\
\hline $\begin{array}{l}\text { Switch } \\
\text { immediately } \\
\text { following } \\
\text { participle }\end{array}$ & 13 & $13.98 \%$ & 6 & $21.43 \%$ & 9 & $8.49 \%$ & 28 & $18.67 \%$ \\
\hline $\begin{array}{l}\text { Switch } \\
\text { elsewhere }\end{array}$ & 63 & $67.74 \%$ & 19 & $67.86 \%$ & 80 & $75.47 \%$ & 106 & $70.67 \%$ \\
\hline Total & 93 & $100 \%$ & 28 & $100 \%$ & 106 & $100 \%$ & 150 & $100 \%$ \\
\hline
\end{tabular}


1221 Table 2. Sample items in grammatical competency tests

Sample item from the MELICET

Sample item from the DELE

"What is that thing?"

"That a spider."
a) to call
b) for calling
c) be called
d) is called

En la compañía se está decidiendo estos días si_nuevos horarios para los trabajadores.

a) haya

b) habrá

'These days the Company is deciding whether new schedules for the workers.
a) there were
b) there will be' 
1223 Table 3. Participant characteristics

\begin{tabular}{lll}
\hline Characteristics & $\begin{array}{l}\text { Early exposure } \\
\text { participants } \\
(\mathrm{n}=42)\end{array}$ & $\begin{array}{l}\text { Late exposure } \\
\text { participants } \\
(\mathrm{n}=27)\end{array}$ \\
\hline Age & $21(18-33)$ & $22(18-32)$ \\
Self-ratings for English proficiency $(/ 10)$ & $9.0(5.75-10)$ & $8.5(5.75-10)$ \\
Self-ratings for Spanish proficiency $(/ 10)$ & $8.3(5.75-10)$ & $9.4(7.5-10)$ \\
BNT score for English (/30) & $20(9-27)$ & $16(8-23)$ \\
BNT score for Spanish $(/ 30)$ & $14(7-24)$ & $21(17-26)$ \\
MELICET score $(/ 50)$ & $40(30-50)$ & $41(30-47)$ \\
DELE score $(/ 50)$ & $35(20-45)$ & $43(33-48)$ \\
\hline
\end{tabular}
1224

$1225 *$ Means are displayed with ranges in parentheses. 
1226 Table 4. Example of experimental item set

Condition Sample sentence

(1) ProgressiveEl chef piensa que los turistas are enjoying the food at his Switch at auxiliary gourmet restaurant.

(2) ProgressiveSwitch at participle El chef piensa que los turistas están enjoying the food at his gourmet restaurant.

(3) PerfectEl chef piensa que los turistas have enjoyed the food at his Switch at auxiliary gourmet restaurant.

(4) PerfectEl chef piensa que los turistas han enjoyed the food at his Switch at participle gourmet restaurant. 
1228 Table 5. Results of the linear mixed-effects models for the sentence initial region (Region 1)

\begin{tabular}{|c|c|c|c|c|}
\hline Measure & Variable & $b$ & SE & $t$ \\
\hline \multirow[t]{8}{*}{ First-pass } & Intercept & 1097.18 & 62.35 & 17.6 \\
\hline & Switch Position & 28.12 & 42.2 & 0.62 \\
\hline & Auxiliary Type & 52.51 & 55.94 & 0.94 \\
\hline & Group & -189.92 & 91.66 & -2.07 \\
\hline & Switch Position * Auxiliary & -21.81 & 62.08 & -0.35 \\
\hline & Switch Position $*$ Group & -65.58 & 72.56 & -0.9 \\
\hline & Auxiliary * Group & -136.1 & 71.23 & -1.91 \\
\hline & Switch Position * Auxiliary * Group & 134.09 & 99.43 & 1.35 \\
\hline \multirow[t]{8}{*}{ Total Time } & Intercept & 2436.9 & 142.22 & 17.13 \\
\hline & Switch Position & -4.35 & 118.5 & -0.04 \\
\hline & Auxiliary Type & 65.02 & 138.19 & 0.47 \\
\hline & Group & -658.39 & 215.71 & -3.05 \\
\hline & Switch Position * Auxiliary & -114.12 & 159.9 & -0.71 \\
\hline & Switch Position $*$ Group & -5.96 & 179.5 & -0.03 \\
\hline & Auxiliary * Group & -37.43 & 197.79 & -0.19 \\
\hline & Switch Position * Auxiliary * Group & 192.02 & 240.61 & 0.8 \\
\hline
\end{tabular}

$1229 *$ Results for the linear mixed-effects models on first-pass reading time and total time. All 1230 predictor variables were contrast coded $(-0.5=$ switch at auxiliary; progressive auxiliary; late 1231 exposure group). Significant $t$-values are bolded. 
1232 Table 6. Results of the linear mixed-effects models for the embedded subject region (Region 2)

\begin{tabular}{|c|c|c|c|c|}
\hline Measure & Variable & $b$ & SE & $t$ \\
\hline \multirow[t]{8}{*}{ First-pass } & Intercept & 638.44 & 39.56 & 16.14 \\
\hline & Switch Position & 15.28 & 33.76 & 0.45 \\
\hline & Auxiliary Type & -0.77 & 40.91 & -0.02 \\
\hline & Group & -133.67 & 54.06 & -2.47 \\
\hline & Switch Position * Auxiliary & -3.63 & 45.64 & -0.08 \\
\hline & Switch Position * Group & -16.63 & 50.81 & -0.33 \\
\hline & Auxiliary * Group & 53.67 & 46.52 & 1.15 \\
\hline & Switch Position * Auxiliary * Group & -25.08 & 68.2 & -0.37 \\
\hline \multirow[t]{8}{*}{ Total Time } & Intercept & 1221.11 & 75.51 & 16.17 \\
\hline & Switch Position & -34.4 & 64 & -0.54 \\
\hline & Auxiliary Type & 56.02 & 80.7 & 0.69 \\
\hline & Group & -281.69 & 106.53 & -2.64 \\
\hline & Switch Position * Auxiliary & -30.85 & 83.11 & -0.37 \\
\hline & Switch Position * Group & 17.73 & 96.34 & 0.18 \\
\hline & Auxiliary * Group & 39.16 & 101.62 & 0.39 \\
\hline & Switch Position * Auxiliary * Group & 38.13 & 123.5 & 0.31 \\
\hline
\end{tabular}

$1233 *$ Results for the linear mixed-effects models on first-pass reading time and total time. All 1234 predictor variables were contrast coded ( $-0.5=$ switch at auxiliary; progressive auxiliary; late 1235 exposure group). Significant $t$-values are bolded. 
1236 Table 7. Mean reading times and standard error on the critical region (participle, Region 3)

\begin{tabular}{llll}
\hline Measure & Switch Position & Late Exposure & Early Exposure \\
\hline \multicolumn{2}{l}{ Progressive structure, e.g., los turistas are enjoying, los turistas están enjoying } \\
First-pass & At Auxiliary & $368(16.75)$ & $350(14.78)$ \\
& At Participle & $409(18.83)$ & $388(14.49)$ \\
Total Time & At Auxiliary & $674(29.78)$ & $683(34.97)$ \\
& At Participle & $732(40.31)$ & $750(29.09)$ \\
\hline
\end{tabular}

Perfect structure, e.g., los turistas have enjoyed, los turistas han enjoyed

$\begin{array}{llll}\text { First-pass } & \text { At Auxiliary } & 355(16.59) & 311(11.95) \\ & \text { At Participle } & 440(24.60) & 438(19.10) \\ \text { Total Time } & \text { At Auxiliary } & 679(36.05) & 636(26.71) \\ & \text { At Participle } & 952(46.12) & 947(39.32)\end{array}$

$1238 *$ Mean reading times in milliseconds for first-pass reading time and total time split by bilingual 1239 group with standard error presented in parentheses. Progressive conditions appear in the upper 1240 panel and Perfect conditions are presented in the lower panel. 
1241 Table 8. Results of the linear mixed-effects models for the critical region (participle, Region 3)

\begin{tabular}{|c|c|c|c|c|}
\hline Measure & Variable & $b$ & SE & $t$ \\
\hline \multirow[t]{8}{*}{ First-pass* } & Intercept & 348.75 & 24.83 & 14.05 \\
\hline & Switch Position & 40.72 & 24.35 & 1.67 \\
\hline & Auxiliary Type & -39.1 & 24.74 & -1.58 \\
\hline & Group & 24.46 & 36.77 & 0.67 \\
\hline & Switch Position * Auxiliary & 85.18 & 36.93 & 2.31 \\
\hline & Switch Position $*$ Group & 1.52 & 38.94 & 0.04 \\
\hline & Auxiliary * Group & 18.78 & 33.71 & 0.56 \\
\hline & Switch Position $*$ Auxiliary $*$ Group & -35.8 & 58.91 & -0.61 \\
\hline \multirow[t]{8}{*}{ Total Time } & Intercept & 681.28 & 51.02 & 13.35 \\
\hline & Switch Position & 72.37 & 40.39 & 1.79 \\
\hline & Auxiliary Type & -41.1 & 52.41 & -0.78 \\
\hline & Group & 11.33 & 72.09 & 0.16 \\
\hline & Switch Position * Auxiliary & 241.17 & 64.55 & 3.74 \\
\hline & Switch Position $*$ Group & -15.89 & 64.68 & -0.25 \\
\hline & Auxiliary $*$ Group & 27.84 & 64.69 & 0.43 \\
\hline & Switch Position $*$ Auxiliary * Group & -17.5 & 102.98 & -0.17 \\
\hline
\end{tabular}

$1242 *$ Results for the linear mixed-effects models on first-pass reading time and total time. All 1243 predictor variables were contrast coded $(-0.5=$ switch at auxiliary; progressive auxiliary; late 1244 exposure group). Significant $t$-values are bolded. The model that converged with first-pass 1245 reading time included random intercepts for Items. 
1246 Table 9. Mean reading times and standard error on the first word post-participle region (Region $1247 \quad 4)$

\begin{tabular}{llll}
\hline Measure & Switch Position & Late Exposure & Early Exposure \\
\hline Progressive structure, e.g., los turistas are enjoying, los turistas están enjoying \\
First-pass & At Auxiliary & $107(9.97)$ & $129(10.02)$ \\
& At Participle & $117(13.23)$ & $131(9.35)$ \\
Total Time & At Auxiliary & $207(16.02)$ & $239(15.5)$ \\
& At Participle & $248(20.71)$ & $250(17.28)$
\end{tabular}

Perfect structure, e.g., los turistas have enjoyed, los turistas han enjoyed

$\begin{array}{llll}\text { First-pass } & \text { At Auxiliary } & 108(9.89) & 123(8.68) \\ & \text { At Participle } & 158(15.74) & 162(11.39) \\ \text { Total Time } & \text { At Auxiliary } & 263(27.65) & 243(14.77) \\ & \text { At Participle } & 347(29.66) & 332(18.43)\end{array}$

$1249 *$ Mean reading times in milliseconds for first-pass reading time and total time split by bilingual 1250 group with standard error presented in parentheses. Progressive conditions appear in the upper 1251 panel and Perfect conditions are presented in the lower panel. 
1253 Table 10. Results of the linear mixed-effects models for the first word post-participle region 1254 (Region 4)

\begin{tabular}{|c|c|c|c|c|}
\hline Measure & Variable & $b$ & SE & $t$ \\
\hline \multirow[t]{8}{*}{ First-pass } & Intercept & 130.46 & 13.99 & 9.33 \\
\hline & Switch Position & 3.74 & 13.18 & 0.28 \\
\hline & Auxiliary Type & -6.47 & 16.94 & -0.38 \\
\hline & Group & -20.17 & 18.63 & -1.08 \\
\hline & Switch Position * Auxiliary & 32.1 & 18.59 & 1.73 \\
\hline & Switch Position * Group & 5.16 & 20.89 & 0.25 \\
\hline & Auxiliary * Group & 0.91 & 20.73 & 0.04 \\
\hline & Switch Position * Auxiliary * Group & 13.04 & 29.39 & 0.44 \\
\hline \multirow[t]{8}{*}{ Total Time } & Intercept & 241.08 & 26.22 & 9.19 \\
\hline & Switch Position & 10.33 & 22.21 & 0.47 \\
\hline & Auxiliary Type & 8.61 & 31.49 & 0.27 \\
\hline & Group & -29.02 & 34.62 & -0.84 \\
\hline & Switch Position * Auxiliary & 72.14 & 31.8 & 2.27 \\
\hline & Switch Position * Group & 30.11 & 35.63 & 0.85 \\
\hline & Auxiliary * Group & 45.79 & 37.73 & 1.21 \\
\hline & Switch Position * Auxiliary * Group & -27.56 & 50.88 & -0.54 \\
\hline
\end{tabular}

$1255 *$ Results for the linear mixed-effects models on first-pass reading time and total time. All 1256 predictor variables were contrast coded $(-0.5=$ switch at auxiliary; progressive auxiliary; late 1257 exposure group). Significant $t$-values are bolded. 
1258 Table 11. Results of the linear mixed-effects models for the second word post-participle region 1259 (Region 5)

\begin{tabular}{|c|c|c|c|c|}
\hline Measure & Variable & $b$ & SE & $t$ \\
\hline \multirow[t]{8}{*}{ First-pass } & Intercept & 277.02 & 17.57 & 15.77 \\
\hline & Switch Position & 16.73 & 16.4 & 1.02 \\
\hline & Auxiliary Type & -1.19 & 21.5 & -0.06 \\
\hline & Group & 45.06 & 22.69 & 1.99 \\
\hline & Switch Position $*$ Auxiliary & 4.09 & 23.6 & 0.17 \\
\hline & Switch Position * Group & 9.17 & 25.9 & 0.35 \\
\hline & Auxiliary * Group & -1.9 & 25.23 & -0.08 \\
\hline & Switch Position $*$ Auxiliary $*$ Group & -21.7 & 37.18 & -0.58 \\
\hline \multirow[t]{8}{*}{ Total Time } & Intercept & 505.45 & 39.46 & 12.81 \\
\hline & Switch Position & 11.25 & 31.7 & 0.36 \\
\hline & Auxiliary Type & 21.97 & 48.01 & 0.46 \\
\hline & Group & 25.48 & 46.69 & 0.55 \\
\hline & Switch Position * Auxiliary & 20.89 & 41.9 & 0.5 \\
\hline & Switch Position * Group & 27.35 & 50.41 & 0.54 \\
\hline & Auxiliary $*$ Group & 7.7 & 48.04 & 0.16 \\
\hline & Switch Position * Auxiliary * Group & -23.38 & 66.41 & -0.35 \\
\hline
\end{tabular}

$1260 *$ Results for the linear mixed-effects models on first-pass reading time and total time. All 1261 predictor variables were contrast coded (-0.5 = switch at auxiliary; progressive auxiliary; late 1262 exposure group). Significant $t$-values are bolded. 


\section{Figures}

1265 Figure 1. Sample questions in LHQ

Did you begin to speak both English and Spanish before age 5?

Yes

No

In general, which language do you prefer to use?

English

Spanish

Both

It depends on whom I talk to

Code-switching means using both Spanish and English in the same sentence when you are talking to someone else. Do you ever code-switch?

$$
\begin{aligned}
& \text { Yes } \\
& \text { No }
\end{aligned}
$$

Why do you think you code-switch? 
Color figure for Online version:

1269 Figure 2. Mean first-pass reading time on the critical region (participle, Region 3)

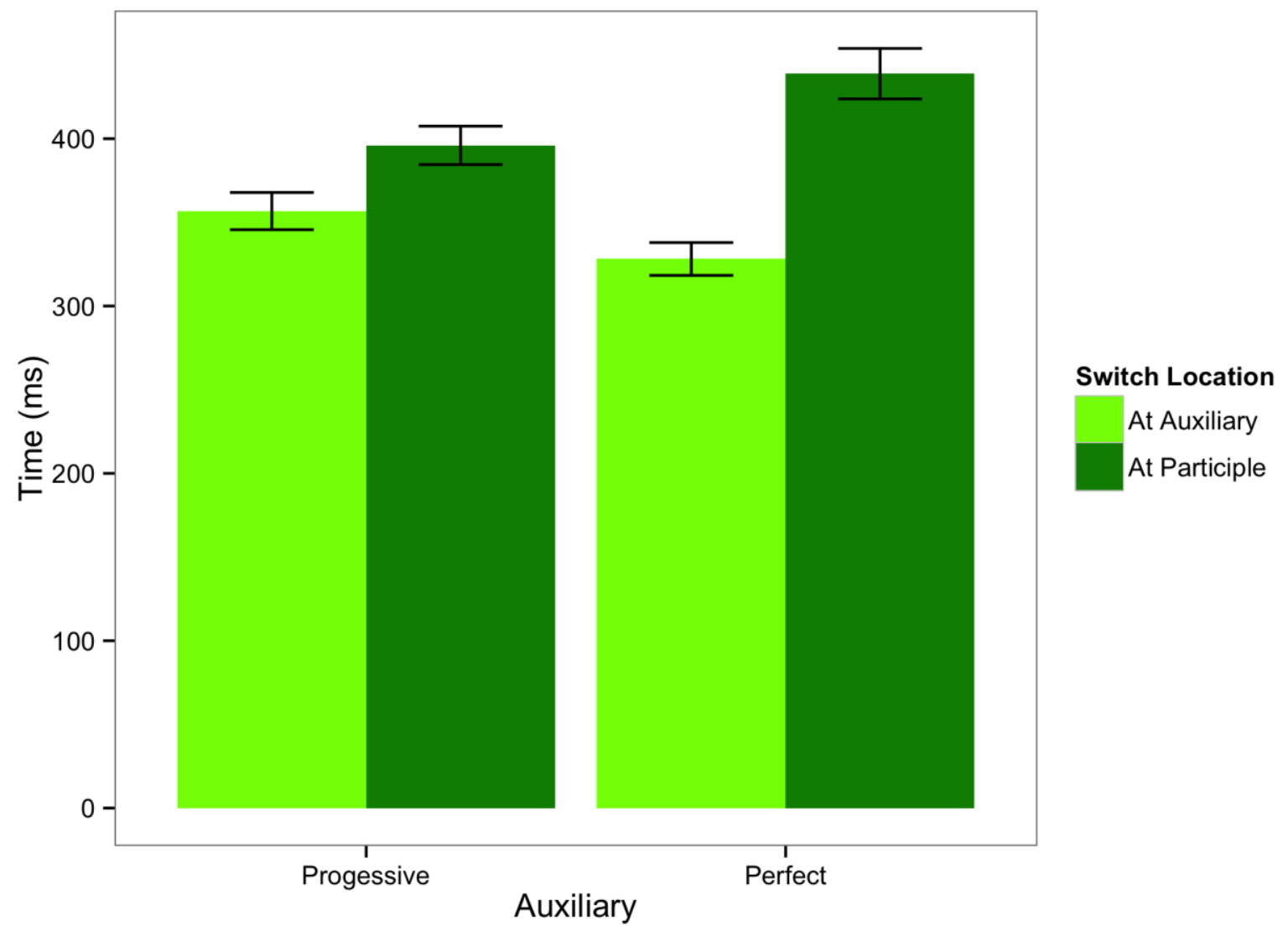

$1271 *$ Mean reading times in milliseconds are presented for first-pass reading time on the participle 1272 for code-switches involving the progressive (arelestán) and perfect (have/han) structures 1273 collapsed for bilingual group. For each auxiliary type, switches at the auxiliary (los turistas are 1274 enjoying / have enjoyed) are presented on the left. Error bars represent standard error of the 1275 mean. 
Black-and-white figure for Print version:

1278 Figure 2. Mean first-pass reading time on the critical region (participle, Region 3)

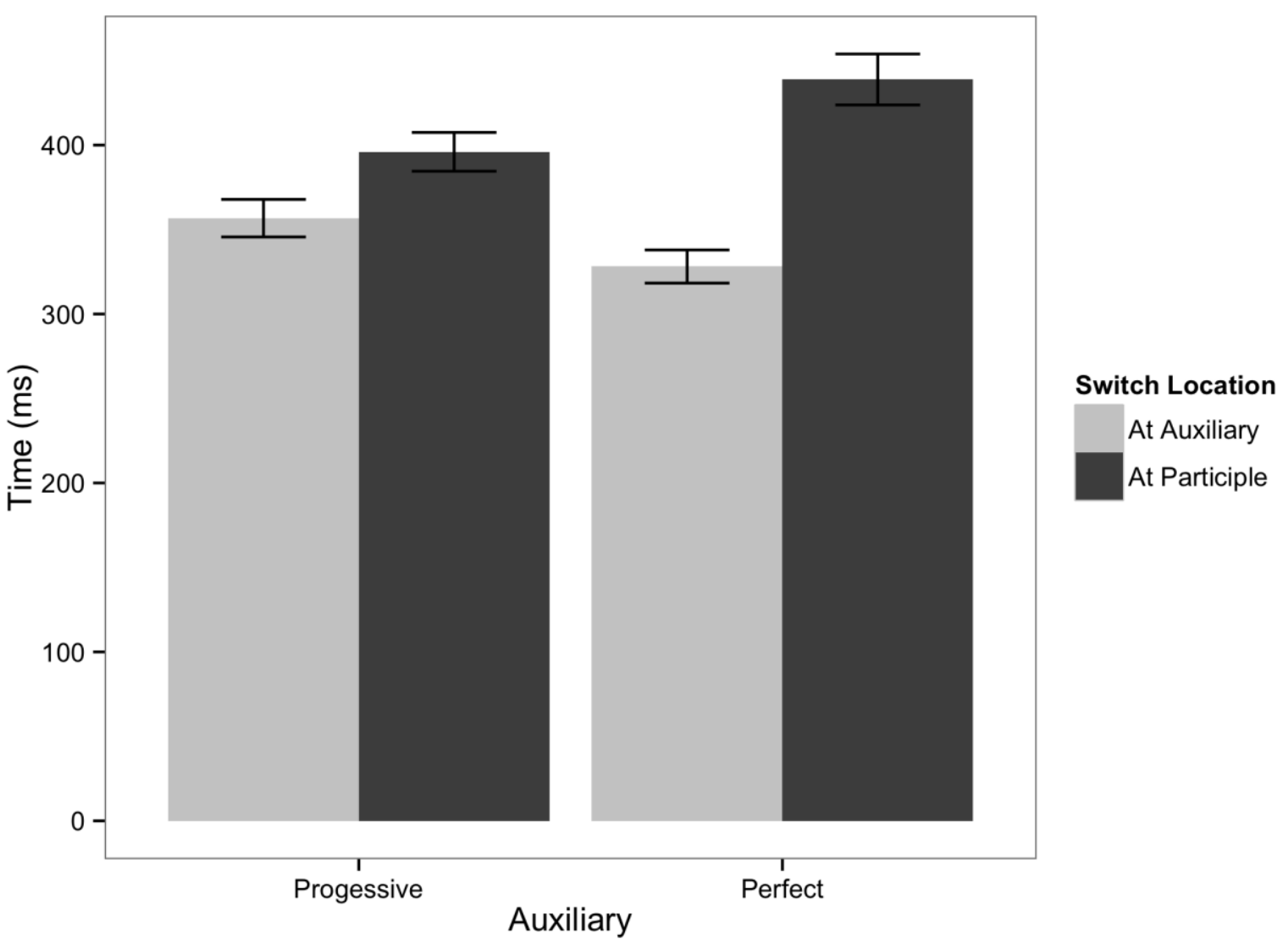

$1280 *$ Mean reading times in milliseconds are presented for first-pass reading time on the participle 1281 for code-switches involving the progressive (are/están) and perfect (have/han) structures collapsed for bilingual group. For each auxiliary type, switches at the auxiliary (los turistas are enjoying / have enjoyed) are presented on the left. Error bars represent standard error of the mean. 
Color figure for Online version:

Figure 3. Mean total time on the critical region (participle, Region 3)

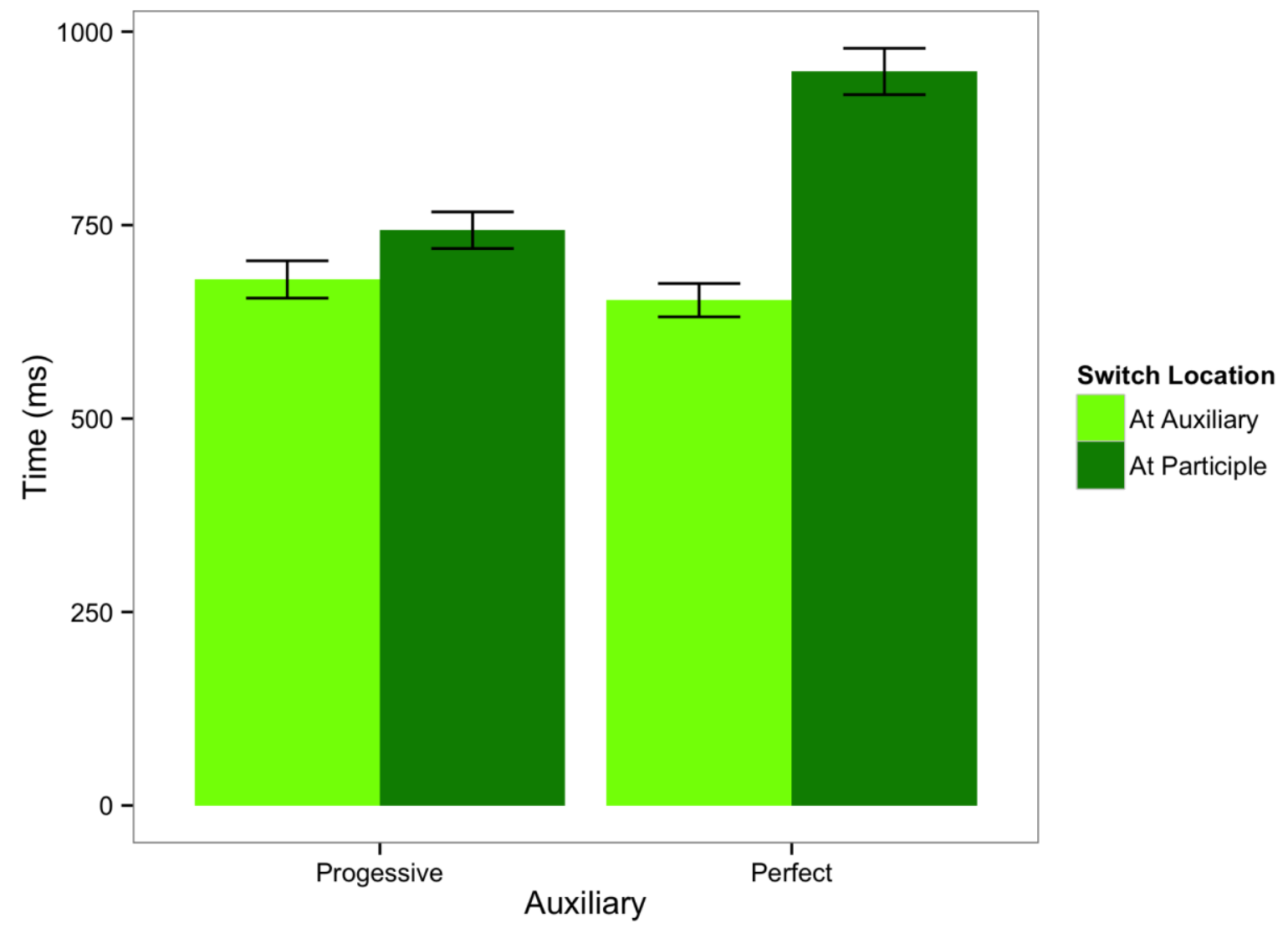

$1289 *$ Mean reading times in milliseconds are presented for total time on the participle for code1290 switches involving the progressive (are/están) and perfect (have/han) structures collapsed for 1291 bilingual group. For each auxiliary type, switches at the auxiliary (los turistas are enjoying / have 1292 enjoyed) are presented on the left. Error bars represent standard error of the mean. 
Black-and-white figure for Print version:

Figure 3. Mean total time on the critical region (participle, Region 3)

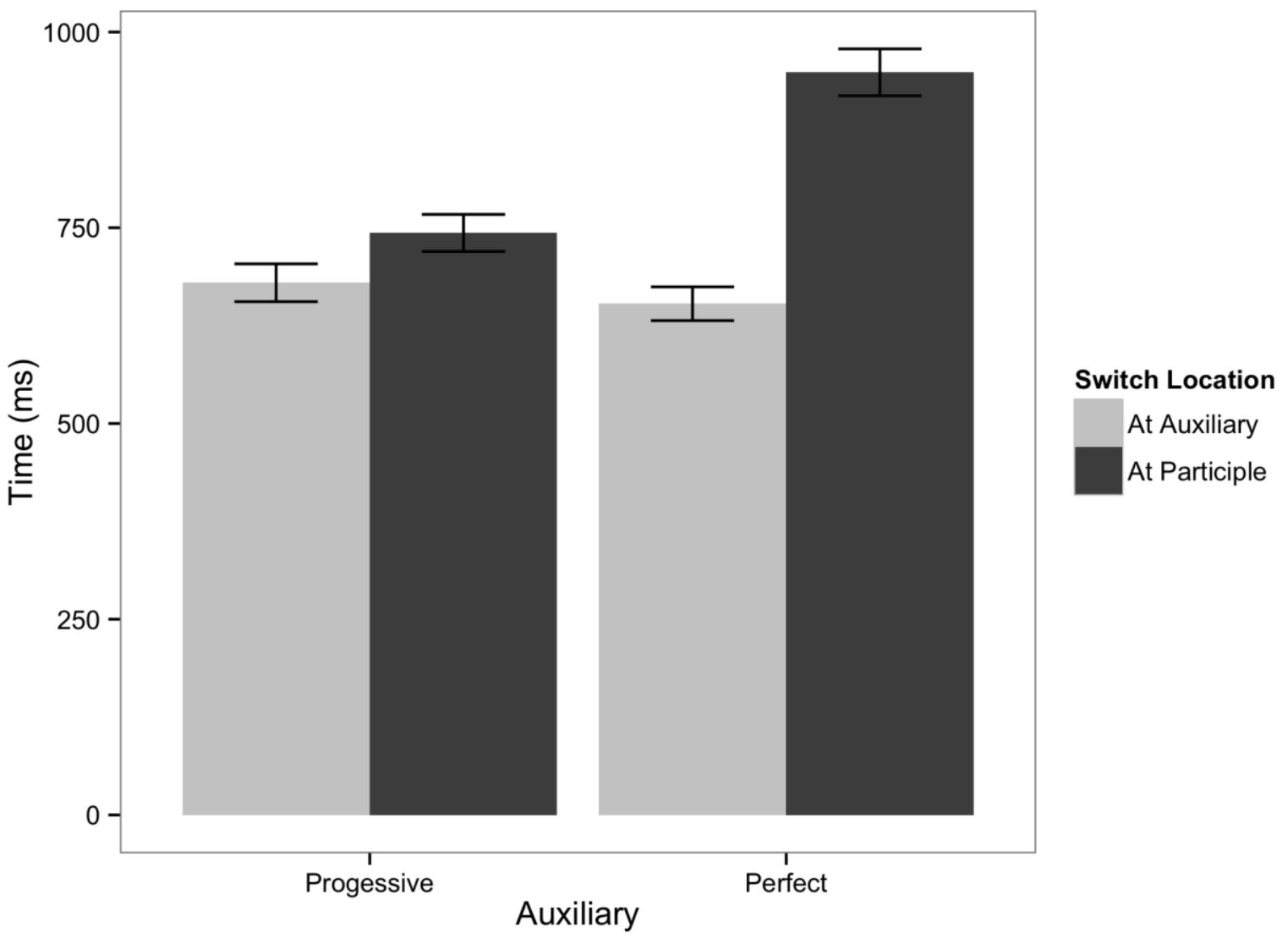

* Mean reading times in milliseconds are presented for total time on the participle for codeswitches involving the progressive (are/están) and perfect (have/han) structures collapsed for bilingual group. For each auxiliary type, switches at the auxiliary (los turistas are enjoying / have enjoyed) are presented on the left. Error bars represent standard error of the mean. 
Color figure for Online version:

Figure 4. Mean first-pass reading time on the first word post-participle region (Region 4)

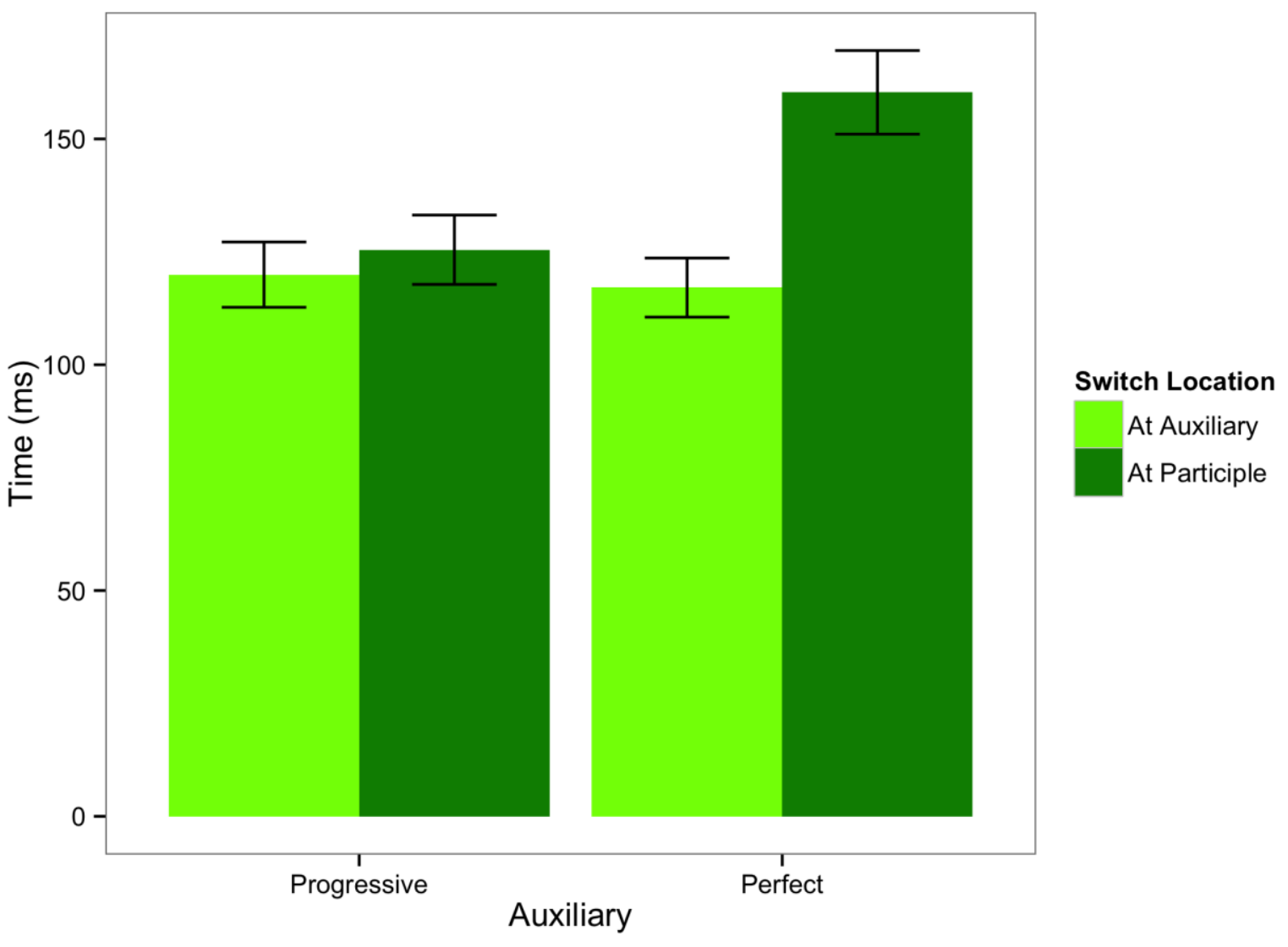

$1307 *$ Mean reading times in milliseconds are presented for first-pass reading time on the first word 1308 post-participle for code-switches involving the progressive (are/están) and perfect (have/han) 1309 structures collapsed for bilingual group. For each auxiliary type, switches at the auxiliary (los 1310 turistas are enjoying / have enjoyed) are presented on the left. Error bars represent standard error 1311 of the mean. 
1314 Black-and-white figure for Print version:

Figure 4. Mean first-pass reading time on the first word post-participle region (Region 4)

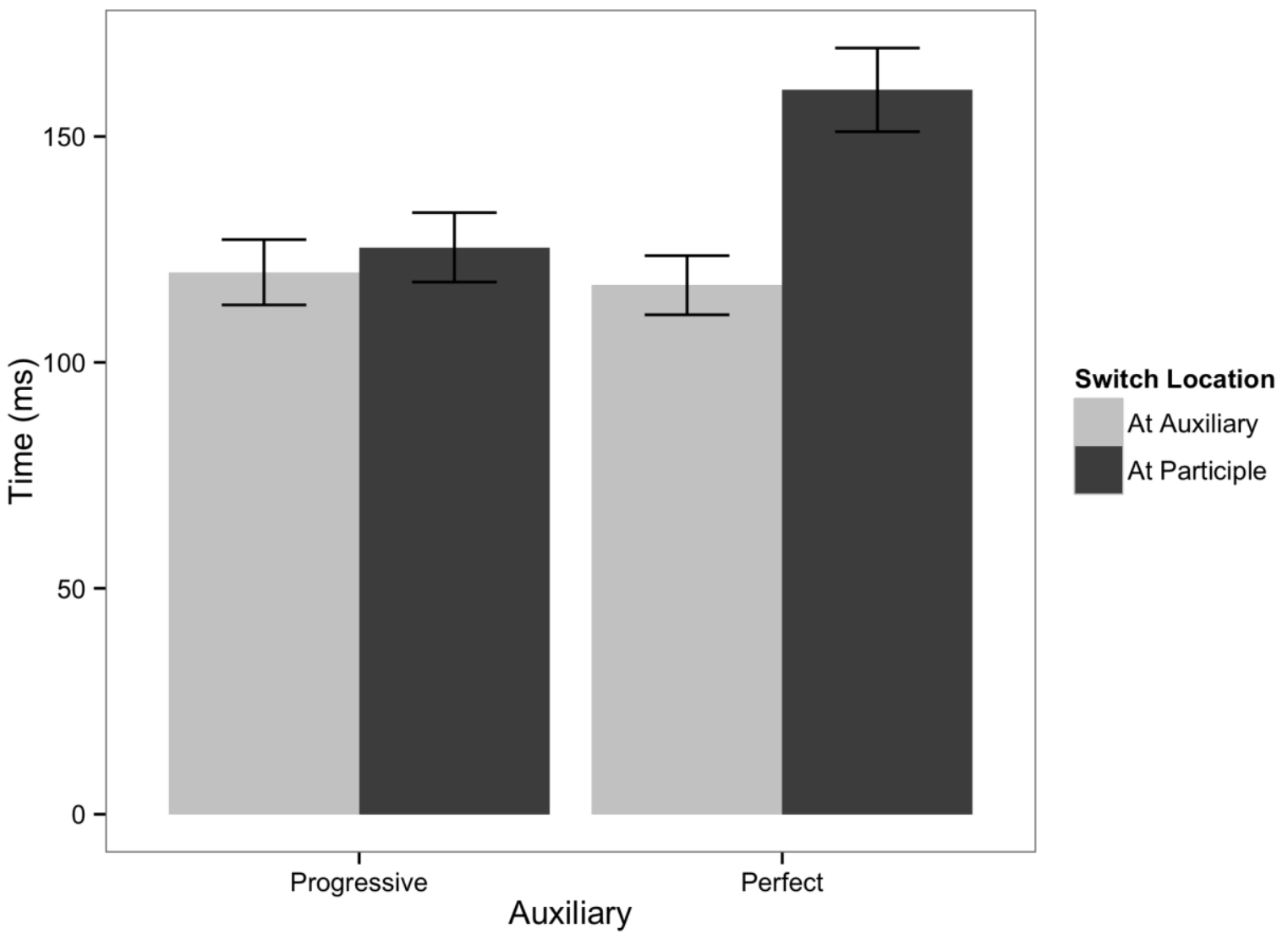

$1318 *$ Mean reading times in milliseconds are presented for first-pass reading time on the first word 1319 post-participle for code-switches involving the progressive (are/están) and perfect (have/han) 1320 structures collapsed for bilingual group. For each auxiliary type, switches at the auxiliary (los 1321 turistas are enjoying / have enjoyed) are presented on the left. Error bars represent standard error 1322 of the mean. 
Color figure for Online version:

Figure 5. Mean total time on the first word post-participle region (Region 4)

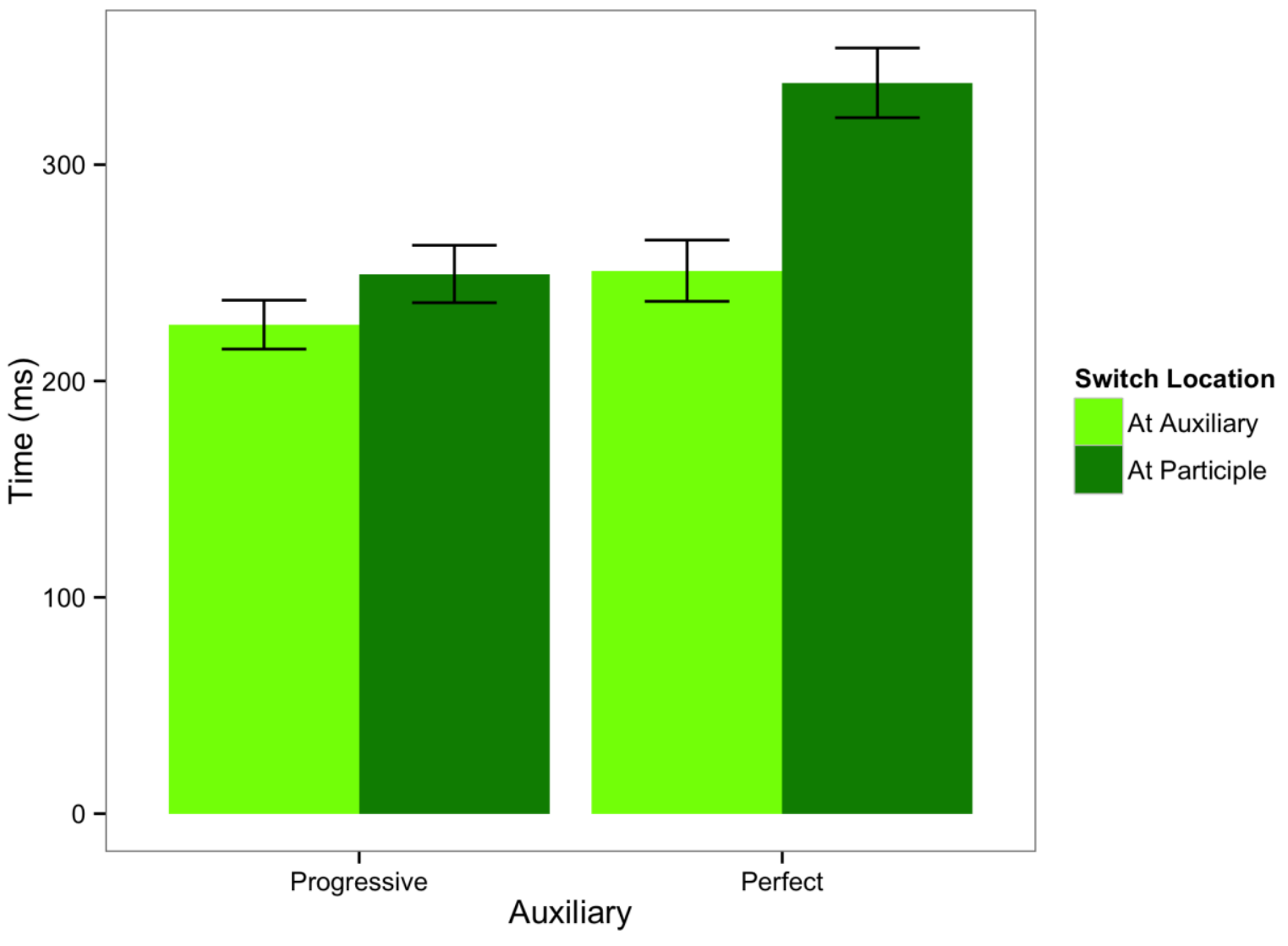

$1328 *$ Mean reading times in milliseconds are presented for total time on the first word post-participle 1329 for code-switches involving the progressive (are/están) and perfect (have/han) structures 1330 collapsed for bilingual group. For each auxiliary type, switches at the auxiliary (los turistas are 1331 enjoying / have enjoyed) are presented on the left. Error bars represent standard error of the 1332 mean. 
Black-and-white figure for Print version:

Figure 5. Mean total time on the first word post-participle region (Region 4)

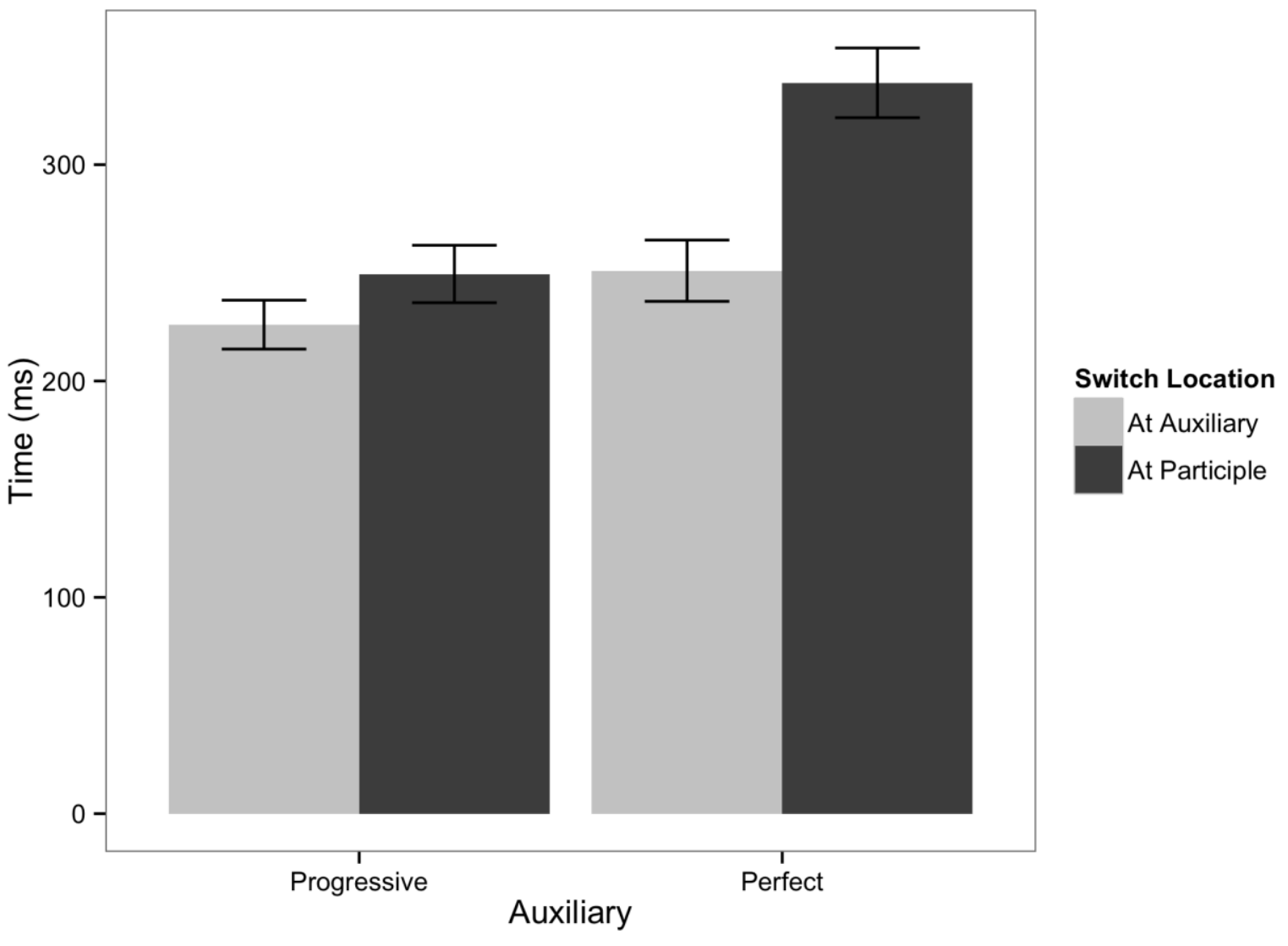

1336

* Mean reading times in milliseconds are presented for total time on the first word post-participle for code-switches involving the progressive (arelestán) and perfect (have/han) structures collapsed for bilingual group. For each auxiliary type, switches at the auxiliary (los turistas are enjoying / have enjoyed) are presented on the left. Error bars represent standard error of the mean. 


\section{Appendix. Experimental item sets}

El abogado descubrió que los criminales are bribing / están bribing / have bribed / han bribed the policeman to destroy the evidence.

'The lawyer discovered that the criminals...'

El abogado garantizó que los criminales are improving / están improving / have improved / han improved their behavior in jail.

'The lawyer guaranteed that the criminals...'

El arquitecto supone que los pintores are considering / están considering / have considered / han considered the colors for the house.

'The architect supposes that the painters...'

El carcelero dijo que los prisioneros are washing / están washing / have washed / han washed their clothes for the week.

'The warden said that the prisoners...'

El chef piensa que los turistas are enjoying / están enjoying / have enjoyed / han enjoyed the food at his gourmet restaurant.

'The chef thinks that the tourists...'

El compositor dice que los pianistas are practicing / están practicing / have practiced / han practiced the symphony for the concert.

'The composer says that the pianists...'

El consejero dijo que sus estudiantes are presenting / están presenting / have presented / han presented their results at the conference.

'The adviser said that his/her students...'

El contador cree que los banqueros are negotiating / están negotiating / have negotiated / han negotiated the loan for the clients.

'The accountant believes that the bankers...'

El contador piensa que los banqueros are preparing / están preparing / have prepared / han prepared the report for the supervisors.

'The accountant thinks that the bankers...'

El decano notó que las recepcionistas are filing / están filing / have filed / han filed the applications in alphabetical order.

'The dean noticed that the receptionists...'

El director afirmó que los técnicos are repairing / están repairing / have repaired / han repaired the photocopiers in the school library.

'The principal affirmed that the technicians...' 
El director dijo que los instructores are preparing / están preparing / have prepared / han prepared the exam for the students.

El director dijo que los productores are preparing / están preparing / have prepared / han prepared the set for the movie.

'The director said that the producers...'

El dueño dijo que los arquitectos are signing / están signing / have signed / han signed the documents for the construction.

'The owner said that the architects...'

El editor notó que los voluntarios are arranging / están arranging / have arranged / han arranged the photographs for the Entertainment section.

'The editor noticed that the volunteers...'

El empleado supone que sus colegas are notifying / están notifying / have notified / han notified their boss of the accident.

'The employee supposes that his colleagues...'

El entrenador dijo que los atletas are ignoring / están ignoring / have ignored / han ignored the remarks from the opposing team.

'The coach said that the athletes...'

El entrenador mencionó que los atletas are practicing / están practicing / have practiced / han practiced five hours a day.

'The coach said that the athletes...'

El entrenador notó que los atletas are grabbing / están grabbing / have grabbed / han grabbed their uniforms from the pile.

'The coach noticed that the athletes...'

El entrenador piensa que los atletas are celebrating / están celebrating / have celebrated / han celebrated their win at the bar.

'The coach thinks that the athletes...'

El general mencionó que los veteranos are enjoying / están enjoying / have enjoyed / han enjoyed the celebration in their honor.

'The general mentioned that the veterans...'

El gerente notó que los turistas are enjoying / están enjoying / have enjoyed / han enjoyed their stay in the hotel.

'The manager noticed that the tourists...' 
El guardia dijo que los prisioneros are cooking / están cooking / have cooked / han cooked the food in the kitchen.

'The guard said that the prisoners...'

El investigador piensa que los gánsters are shipping / están shipping / have shipped / han shipped the drugs to New York City.

'The investigator thinks that the gangsters...'

El jefe anunció que las secretarias are notifying / están notifying / have notified / han notified the media about the strike.

'The boss announced that the secretaries...'

El locutor dijo que los entrenadores are reaching / están reaching / have reached / han reached their goals with the players.

'The announcer said that the trainers...'

El maestro notó que los estudiantes are copying / están copying / have copied / han copied the answers on their desks.

'The teacher noticed that the students...'

El periodista anunció que los músicos are producing / están producing / have produced / han produced the album in the studio.

'The journalist announced that the musicians...'

El presidente anunció que los senadores are negotiating / están negotiating / have negotiated / han negotiated the terms of the agreement.

'The president announced that the senators...'

El psiquiatra afirmó que los prisioneros are justifying / están justifying / have justified / han justified their behavior in the session.

'The psychiatrist affirmed that the prisoners...'

El reportero confirmó que los senadores are requesting / están requesting / have requested / han requested the funds for the project.

'The reporter confirmed that the senators...'

El reportero dijo que las modelos are signing / están signing / have signed / han signed a contract with the agency.

'The reporter said that the models...'

El sargento garantizó que los detectives are removing / están removing / have removed / han removed the evidence from the crime scene.

'The sergeant guaranteed that the detectives...' 
1478

1479

1480

1481

1482

1483

1484

1485

1486

1487

1488

1489

1490

1491

1492

1493

1494

1495

1496

1497

1498

1499

1500

1501

1502

1503

1504

1505

1506

1507

1508

1509

1510

1511

1512

1513

1514

1515

1516

1517

1518

1519

1520

1521
El sargento garantizó que los soldados are preparing / están preparing / have prepared / han prepared the weapons for the mission.

'The sergeant guaranteed that the soldiers...'

El supervisor mencionó que los carpinteros are fixing / están fixing / have fixed / han fixed the cabinets in the kitchen.

'The supervisor mentioned that the carpenters...'

El vendedor confirmó que los coleccionistas are importing / están importing / have imported / han imported the sculptures from India.

'The seller confirmed that the collectors...'

La enfermera afirmó que los doctores are consulting / están consulting / have consulted / han consulted a specialist about the results.

'The nurse affirmed that the doctors...'

La enfermera descubrió que los cirujanos are deceiving / están deceiving / have deceived / han deceived the patient about his illness.

'The nurse discovered that the surgeons...'

La estilista confirmó que los diseñadores are organizing / están organizing / have organized / han organized their collections for the fashion show.

'The stylist confirmed that the designers...'

La familia notó que los jardineros are planting / están planting / have planted / han planted the trees in the backyard.

'The family noticed that the gardeners...'

La maestra supone que los estudiantes are checking / están checking / have checked / han checked their email in the library.

'The teacher supposes that the students...'

La profesora anunció que los editores are approving / están approving / have approved / han approved her article for the journal.

'The professor announced that the editors...'

La reportera afirmó que los científicos are testing / están testing / have tested / han tested the vaccine on rats.

'The reporter affirmed that the scientists...'

La revista indicó que los actores are answering / están answering / have answered / han answered the letters from their fans.

'The magazine indicated that the actors...' 
1522 La secretaria dijo que los asistentes are accusing / están accusing / have accused / han accused their boss 1523 of fraud.

1524 'The secretary said that the assistants...'

La superintendente garantiza que los instructores are testing / están testing / have tested / han tested the 1527 students appropriately. 'The superintendent guarantees that the instructors...'

Los estudiantes notaron que las profesoras are placing / están placing / have placed / han placed their quizzes on the bookshelf.

'The students noticed that the professors...'

Los inquilinos notaron que los electricistas are fixing / están fixing / have fixed / han fixed the powerlines in the building.

'The tenants noticed that the electricians...' 